IZA DP No. 8475

Managerial Practices and Students' Performance

Adriana Di Liberto

Fabiano Schivardi

Giovanni Sulis

September 2014

Forschungsinstitut zur Zukunft der Arbeit Institute for the Study of Labor 


\title{
Managerial Practices and Students' Performance
}

\author{
Adriana Di Liberto \\ University of Cagliari, \\ IZA and CRENOS
}

\section{Fabiano Schivardi}

Bocconi, IGIER, EIEF

and CEPR

\author{
Giovanni Sulis \\ University of Cagliari \\ and CRENOS
}

\section{Discussion Paper No. 8475 \\ September 2014}

\author{
IZA \\ P.O. Box 7240 \\ 53072 Bonn \\ Germany \\ Phone: +49-228-3894-0 \\ Fax: +49-228-3894-180 \\ E-mail: iza@iza.org
}

\begin{abstract}
Any opinions expressed here are those of the author(s) and not those of IZA. Research published in this series may include views on policy, but the institute itself takes no institutional policy positions. The IZA research network is committed to the IZA Guiding Principles of Research Integrity.
\end{abstract}

The Institute for the Study of Labor (IZA) in Bonn is a local and virtual international research center and a place of communication between science, politics and business. IZA is an independent nonprofit organization supported by Deutsche Post Foundation. The center is associated with the University of Bonn and offers a stimulating research environment through its international network, workshops and conferences, data service, project support, research visits and doctoral program. IZA engages in (i) original and internationally competitive research in all fields of labor economics, (ii) development of policy concepts, and (iii) dissemination of research results and concepts to the interested public.

IZA Discussion Papers often represent preliminary work and are circulated to encourage discussion. Citation of such a paper should account for its provisional character. A revised version may be available directly from the author. 
IZA Discussion Paper No. 8475

September 2014

\section{ABSTRACT}

\section{Managerial Practices and Students' Performance*}

We study the effects of managerial practices in schools on students' outcomes. We measure managerial practices using the World Management Survey, a methodology that enables us to construct robust measures of management quality comparable across countries. We find substantial heterogeneity in managerial practices across six industrialized countries, with more centralized systems (Italy and Germany) lagging behind the more autonomous ones (Canada, Sweden, the UK, the US). For Italy, we are able to match organizational practices at the school level with students' outcomes in a math standardized test. We find that managerial practices are positively related to students' outcomes. The estimates imply that if Italy had the same managerial practices as the UK (the best performer), it would close the gap in the math OECD-PISA test with respect to the OECD average. We argue that our results are robust to selection issues and show that they are confirmed by a set of IV estimates and by a large number of robustness checks. Overall, our results suggest that policies directed at improving students' cognitive achievements should take into account principals' selection and training in terms of managerial capabilities.

JEL Classification: L2, I2, M1, O32

Keywords: management, productivity, school principals, cognitive skills

Corresponding author:

Adriana Di Liberto

Department of Economics and Business

University of Cagliari

Viale S. Ignazio da Laconi 78

Cagliari

Italy

E-mail: diliberto@unica.it

\footnotetext{
* Preliminary version of a paper prepared for the 60th Panel Meeting of Economic Policy, October 2014. We thank Daniele Checchi, Gianfranco De Simone, Andrea Gavosto, Erik Hanushek, Victor Lavy, Angelo Paletta, Paolo Sestito, Marco Sideri, John Van Reenen and seminar participants at the University of Cagliari, University of Padova, 2013 AlEL Conference (Rome), 2013 Brucchi Luchino Conference (Rome), 2014 RES Conference (Manchester), 2014 ESPE Conference (Braga), 10 Years of the World Management Survey Conference (Cambridge, MA) for very useful comments and discussions. We thank Renata Lemos and Raffaella Sadun for their support in the World Management Survey data collection process and Barbara Dettori for help with the PISA data. We also thank INVALSI and in particular Patrizia Falzetti for providing the data on students outcomes. Sulis acknowledges hospitality at the Center for Labor Economics at Berkeley University. We are solely responsible for all the remaining errors. Financial support from the Regione Sardegna, Legge 7/2007 grant CUP F71J09000300002, and from the Fondazione Giovanni Agnelli is gratefully acknowledged.
} 


\section{Introduction}

The importance of human capital for economic growth is one of the most uncontroversial facts in economics (Lucas, 1988; Barro and Lee, 1994). And human capital is in a large part "produced" in school. It is therefore not surprising that the debate on the determinants of students' performance, and on policies that can improve them, is very lively. However, despite a large amount of work, this debate is far from having reached robust conclusions. Hanushek and Woessmann (2011) review the available empirical studies and conclude that "evidence from both within and across countries points to the positive impact of competition among schools, of accountability and student testing, and of local school autonomy in decision making." However, these factors are conducive to better students' achievement only in well-developed school systems (Hanushek, Link, and Woessmann, 2011). In fact, only when schools are well managed students can benefits from decentralization, while giving autonomy to badly run institutions can indeed worsen students' outcomes.

Indeed, there is a growing attention regarding the role of school principals (SPs in what follows) as managers in charge of running the school (Bloom et al., 2014). However, we still know relatively little on this issue, because assessing the role of managerial practices on students' outcomes is a difficult task, mostly due to the challenges of measuring such practices. Thus, while there is a large qualitative literature stressing the importance of the role of SPs and leadership on school's outcome, only few recent studies have attempted to quantify the role played by the SPs on students' outcomes. This paper addresses this question. We collect data on school managerial practices through extensive phone interviews of around 400 Italian SPs of upper secondary schools. The interviews are based on the World Management Survey (Bloom and Van Reenen, 2007, 2010b) data collection method, that allows to score the managerial practices adopted in a given institution. The survey covers 23 specific managerial activities that can be combined to obtain a synthetic measure of management quality and also grouped into five specific management areas: operations, monitoring, targets, incentives and leadership. The double blind and open questions techniques implemented in the World Management Survey enables to obtain high quality data that control for typical problems of self-assessment bias. It has been applied to a large number of both private firms and public institutions in health and education (Bloom et al., 2012, 2014). The data collection method is standardized and allows for meaningful comparisons across countries. This type of data is increasingly used in academic research (Bloom and Van Reenen, 2010a).

We first compare the managerial practices for six countries for which data are available 
(Canada, Germany, Italy, Sweden, the UK and the US). We find substantial heterogeneity in managerial practices across countries, with more centralized systems (Italy and Germany) lagging behind the more autonomous ones, as also found by Bloom et al. (2014). We also show that these cross country differences are not simply due to different institutional constraints that each national schooling system imposes on SPs. For example, we find that the gap of Italian schools practices is not lower in areas where the institutional constraints are less of an issue, such as in planning and monitoring the school objectives, compared to areas in which they are much more binding in some countries than in others, such as in terms of hiring and firing teachers. This suggests that the observed cross country heterogeneity in the quality of managerial practices is at least partially due to difference in underlying SPs abilities. This in turn can be attributed to the different selection and/or the training mechanisms in place in different countries.

For the Italian data, we are able to match the indicators of managerial practices with tenth grade students' results in a standardized math test administrated by the INVALSI, the Italian institute in charge of evaluating schools' performance. The Italian case is an interesting one to study the effects of SPs' managerial practices on students' outcomes. First, there is substantial geographical heterogeneity in both quantitative (educational attainments) and qualitative (cognitive skill tests results) educational outcomes. Second, as we argue in detail in the paper, the process of assignment of SPs to schools greatly reduces endogeneity concerns, according to which the most capable SPs are assigned to the best schools. In fact, we have access to a rich set of covariates at the school, SP, and individual student level, that should control for the most likely selection issues. Moreover, SPs are assigned through an informal process based mostly on seniority, a characteristic we can control for. Finally, we use the reforms of the Italian school system to construct an IV regression.

Our baseline model is an OLS regression of students' performance on the indicator of overall managerial practices (obtained as the mean of all the areas surveyed in the interview), controlling for a large number of school, SPs and students' characteristics. Data on students' performance are the test scores for Maths expressed as percentage of right answers. We find that the indicator of managerial practices has a positive coefficient of 2.24 , significant at $10 \%$. Given that the test results are between 0 and 100, with a sample average of 49.04, the estimated coefficient can be readily interpreted in terms of increased test score results. It implies that a unit increase in the indicator of managerial practices (which has mean 2.01 and s.d. of .5) would improve the students' average test score results by $4.6 \%$, 
approximately the distance of Italian students from the OECD average in the standardized OECD PISA tests. While a unit increase in managerial practices is clearly substantial, it is also approximately the distance from the average value in Italy and the UK, the country with the highest score.

In terms of specific areas of managerial practices, we find that the effects are positive in all categories, although statistically significant only for leadership and monitoring activities of school processes. In particular, the fact that we find no significant effect on the incentives section (People), that includes human resource management, is consistent with the high degree of institutional constraints that Italian SPs face on this subject.

We perform several robustness checks. First, we use the fact that, starting in 2006, a new national competition was introduced that also explicitly assesses managerial skills. This reform should have an impact on managerial skills of those that became SPs afterwards, while being unrelated to the assignment to specific schools (conditional on controls). We use a dummy for those who became SP after 2006. The IV results confirm the OLS ones, with the effect becoming substantially larger. Second, since students' sorting is more likely to arise in more densely populated areas where schools are in competition, we run a separate analysis for isolated vs non isolated schools. The results are at odds with the sorting explanation. We also replicate our analysis on different sub-samples, namely, of low and high socioeconomic background students, finding that managerial practices impact students performance more in the first category of schools. We consider how the effect of managerial practices varies depending on the importance of institutional constraints, finding that this is indeed the case, and check if cheating behaviour may be driving our main results, ruling out this possibility. We also show that managerial practices affect the distribution of test scores within the school uniformly, shifting the whole distribution to the right. Finally we consider an alternative students' outcome variable and check if good practices play a role on the probability of students lagging behind in the age/grade ladder. All these exercises confirm that management quality is an important input of our estimated education production function.

Our last exercise is to compare the management indicators of the WMS with those that can be obtained from the OECD PISA survey, which contains a section where SPs self assess the quality of management and the degree of autonomy of the school. This is a less demanding way to assess practices and it is available for a large set of countries. It is therefore useful to check if the two surveys supply a similar picture. Unfortunately, this does not seem to be the case. Both the direct comparison between PISA and WMS indicators 
and the regression analysis based on PISA management variables reveal marked differences between the two surveys. These disparities are likely to be due to both methodological differences in data collection and possible mis-measurement of the self-reported PISA managerial indices. They suggest that self assessment cannot substitute the direct assessment of SPs managerial capabilities by a third party.

The rest of the paper is organized as follows. In Section 2 we review the related literature. Section 3 describes the World Management Survey and discusses the channels of action of SPs. Section 4 compares the survey results for the six countries. We describe the students' data and the additional controls in Section 5 and the identification and the empirical design in the following Section 6. Section 7 discusses the main results and Section 8 the extensions and robustness checks. We also compare our management data with the existing measures of school principals leadership provided by the OECD PISA project in Section 9 and finally conclude in Section 10.

\section{Literature review}

The role of the SPs on students' learning is increasingly identified as crucial. Most existing analysis on the role of the SPs on students' performance has been qualitative and only few recent studies have attempted to quantify the role played by the SPs in the results obtained by the students during their school career. ${ }^{1}$ This is due, at least in part, by measurement problems since the identification of SPs efficiency is a difficult empirical issue and results may change significantly depending on the methodology adopted. ${ }^{2}$ Most quantitative studies use the value added approach, a methodology already introduced to estimate the effect of individual teachers on student performance but employed also outside the education framework to identify the role of CEOs in firms productivity. ${ }^{3}$

Using data collected between 1995 and 2001 for a sample of Texas schools, Branch, Hanushek, and Rivkin (2012) estimate the role of principals on student academic achievement using the semi-parametric approach provided by Bertrand and Schoar (2003) in their study of corporate management styles. ${ }^{4}$ They find significant variation in principal quality

\footnotetext{
${ }^{1}$ One of the first studies is Brewer (1993).

${ }^{2}$ Loeb, Kalogrides, and Béteille (2012) compare three measures of SP quality calculated with standard value added methodologies with alternative survey measures of SP performance and find low correlation across the different indicators.

${ }^{3}$ See Chetty, Friedman, and Rockoff (2011) and Rivkin, Hanushek, and Kain (2005) for teachers and Bertrand and Schoar (2003) for CEOs efficiency estimates.

${ }^{4}$ They calculate different measures of SPs efficiency. A first estimate is obtained by introducing effectsby-school principal in a regression model that uses as dependent variable the results on cognitive tests (in both math and reading for students from three to eight grade), while a second specification is obtained by
} 
and identify a large effect, similar to that found for teachers, of principal leadership on student outcomes. ${ }^{5}$ Moreover, SPs quality variance appears to be larger for more disadvantaged schools suggesting that the leadership skills have larger effects in these schools. Significant effects of SPs on students test results have also been found in Coelli and Green (2012) for Canada and Böhlmark, Grönqvist, and Vlachos (2012) for Sweden. Together with students' test outcomes, the latter study also finds that SPs quality significantly affects alternative school outcomes variables and find that SPs in smaller schools have a larger effect on students' test results. ${ }^{6}$

Li (2012) focuses on the labor market dynamics of the principals and shows as testbased accountability systems may significantly change SPs incentives and, through that, their allocation decisions, with unintended consequences on disadvantaged students. In particular, she uses data from the No Child Left Behind (NCLB) policy as implemented in North Carolina that introduced formal sanctions for schools and principals missing specific students' performance targets. ${ }^{7}$ This analysis suggests that the relative change in the riskreward structure of low versus high-performing schools introduced by the new test-based accountability system decreased the average quality of principals serving disadvantaged schools. In fact, principals' pay does not fully adjust to compensate the risks, inducing more able SPs, who are more likely to have the option of working elsewhere, to depart these schools. ${ }^{8}$ Thus, even if one goal of the NCLB policy was to increase the competencies of most disadvantaged students, this study shows that this induced allocation effect may produce exactly the opposite result. The importance of SPs incentives is also investigated by Lavy (2008) who finds that the increase in the salary of high schools principals in Israel led to significant improvements in students' academic achievements. ${ }^{9}$

adding to the previous regression model school fixed effects.

${ }^{5}$ Their lower bound results imply that a principal in the top 16 percent of the quality distribution (or one standard deviation above average) would lead each year to student gains that are 0.05 s.d. or more higher than average for all students in the school. For results on the impact of teachers see Rockoff (2004) and Rivkin, Hanushek, and Kain (2005) among the others.

${ }^{6}$ Specifically, these alternative outcome variables are grade inflation, wage dispersion, the presence of a gender balanced teaching staff, teachers retention rates and teachers on long-term sick leave.

${ }^{7}$ Performance targets, called Adequate Yearly Progress, are set dividing students into 9 demographic subgroups. They require that students in each subgroup reach a particular threshold for reading and math scores. If only one subgroup fails to make this target, the entire school is declared failing. Data shows that for disadvantaged schools it was difficult to improve test scores among every low-performing demographic subgroup.

${ }^{8}$ Unlike other states, North Carolina already had an accountability program in place before the introduction of NCLB but performance targets and sanctions were less binding for principals/schools. Using a different sample, Branch, Hanushek, and Rivkin (2012) do not find strong evidence of more effective leaders having higher probability of exiting more disadvantaged schools.

${ }^{9}$ On this see also Cullen and Mazzeo (2008) and Brewer (1993). 
Unlike the first, the second strand of literature goes more in depth about the specific SPs managerial practices and activities using both teachers/parents survey responses based upon personal perceptions of the principal or SPs self-assessment surveys. In fact, recent studies criticize the excessive attention paid by education scholars to the role played by the SP in supporting teaching activities and conversely stress the importance of more managerial activities. Grissom and Loeb (2011) exploit the answers given to a questionnaire submitted to 314 SPs in the district of Miami who were asked to provide a self-evaluation on a scale from 1 to 4 for the effectiveness in leading the school in 42 specific tasks and find that the more strictly managerial and organizational skills have the greatest impact on educational attainment. Their results are also compared with the answers given by SP's assistants to the same questionnaire as well as alternative indicators of teachers and parents satisfaction with school quality. ${ }^{10}$

In general, both the value added and the survey responses approaches to estimate the SPs effectiveness may be subject to criticisms. In particular, the former approach exploits SPs turnover across schools and requires large longitudinal data sets to observe a sufficient number of principals switches to convincingly identify their quality. This is done to reduce concerns about conflating principal and other school effects that would be present including stayers, that is, principals who are only observed in one school. However, even when long panel data are available, self selection problems may still arise since SPs are not not likely to be randomly assigned to schools: if SPs systematically move in best performing schools (in terms of student test achievement gains) value-added measures of principal efficiency are still biased. ${ }^{11}$ Second, value added measures do not control for the possibility that SPs quality change over time with tenure and experience. ${ }^{12}$ Third, they produce an overall measure of the SPs impact but they do not tell much about what SPs actually do to influence student learning. ${ }^{13}$ As seen above, the survey approach overcome the latter criticism. However, the use of these type of indices raises the concerns over mis-measurement since they suffer from

\footnotetext{
${ }^{10}$ Robinson, Lloyd, and Rowe (2008) conduct two separate meta-analyses and find significant effect of both instructional leadership activities and of more specific management activities on students academic performance.

${ }^{11}$ In this case, such problems conflate the true SP effect with other factors for test results change. However, $\mathrm{Li}$ argues that compared to teachers value-added measures "...these concerns are less of a problem in the context of studying principals. While principals have substantial knowledge about the test scores and other characteristics of students in their own school and may use this information in assigning teachers to classrooms, they have less information about the test score gains of students at other schools and are thus less likely to use this information in their own mobility decisions." Li (2012), p.17.

${ }^{12}$ On this see Li (2012).

${ }^{13}$ This approach enables Branch, Hanushek, and Rivkin (2012) to investigate the relationship between the observed patterns of teacher exits and principals quality.
} 
being based either on (teachers/parents) perceptions or suffer from the typical problems of self-assessment bias. ${ }^{14}$

\section{The role of SPs managerial practices in schools}

In this section we first describe how we measures managerial practices and then we discuss the channels through which they can affect students outcomes.

\subsection{The World Management Survey}

As highlighted in the previous section, the main difficulty encountered when analyzing the effect of SPs on school outcomes is to provide a reliable quantitative measure of SPs' abilities in terms of leadership capacity and organizational skills. While there is an established literature that suggests that such components are important determinants of firms productivity differentials across countries and sectors (Bloom and Van Reenen, 2007, 2010b, 2011), good data on managerial practices in the public sector are hardly available (Bloom et al., 2012, 2014). As a matter of fact, previous studies dealing with the role of SPs and based on the "survey approach" suffer from severe limitations, mostly related to mis-measurement of managerial abilities and self-assessment bias.

Obtaining a robust measure of managerial practices that doesn't suffer from such problems is not a simple task. Bloom and Van Reenen (2007) discuss in detail the main challenges. First, measuring management requires a definition of "good" and "bad" managerial practices which is possibly not contingent on the specific production environment (firms, hospitals, schools) and applicable to different units. Second, managers' responses to survey questions should be unbiased and there should be no preconceptions of interviewers about the performance of the production unit analyzed. Finally, when collecting data on managers operating in the public sector, additional problems related to the institutional constraints limiting their activity should be, to some extent, taken into account.

In this paper we use the survey tool proposed within the international project World Management Survey (WMS henceforth) to obtain quantitative measures of managerial practices adopted by SPs operating in the Italian secondary school system (Bloom et al., 2014). Such innovative tool, initially developed by Bloom and Van Reenen (2007) for the manufacturing sector and subsequently adapted for the service and public sector, is based on a telephone double-blind survey technique and comprises a set of open ended questions

\footnotetext{
14 "...on average principals rated themselves highly on most tasks, a pattern consistent with other principal self-assessment tools." Grissom and Loeb (2011), p. 1100.
} 
that are subsequently evaluated using a scoring grid (Bloom and Van Reenen, 2011, 2010a; Bloom et al., 2012). Qualitative answers of SPs are then recoded into quantitative measures with a score ranging between 1 (worst) to 5 (best managerial practices). The aim of the questionnaire is not that of measuring the intrinsic abilities of the SP, or practices that are too contingent to the specific environment, but the quality of managerial practices adopted. In fact, such approach identifies managerial practices that are common across units, such as schools or firms, and focuses on the solutions adopted by principals/managers to solve specific problems. ${ }^{15}$

The questionnaire, that is reported in Table A2 in the Appendix, comprises five sections that consider different key areas of management practices. ${ }^{16}$ The first section is Leadership (three questions) and measures the leadership capacity of the SP jointly with a clear definition of roles and responsibilities within the school. The second section is Operations (four questions) and is concerned with the standardization of instructional processes, personalization of teaching and adoption of best practices within the school. The third dimension is Monitoring (five questions) and focuses on the monitoring of performance and reviewing the results, the dialogue between components within the school and the consequences of anomalies in the processes. The fourth section is Targets (five questions) and has the objective to assess the managerial capacity of SPs to identify quantitative and qualitative targets, their interconnection and their temporal cascade. Finally, the fifth dimension is People (six questions) and it is specifically concerned with human resource management, ranging from promoting and rewarding employees based on performance, removing poor performers, hiring best teachers, and trying to keep the best ones. ${ }^{17}$

The remaining part of the questionnaire collects data on the main principal and school characteristics. We collected information on demographic characteristics of the SP such as gender, age, tenure in school, experience in post, marital status, teaching field of specialization and place of birth. We also obtained data on the number of students in the school, number of teachers and administrative staff, number of schools in competition, type of school, religious orientation and ownership (private versus public), presence of possible

\footnotetext{
${ }^{15}$ Although the survey is very similar across different sectors, there are differences in terms of specific sections and questions included. We will discuss this issue in more detail in next sections.

${ }^{16}$ The overall management index that we use in the empirical application is calculated as the average of scores obtained in each question. Moreover we calculate an average score for each section of the questionnaire. See sections 4 and 7 below for further details.

${ }^{17}$ The WMS international survey on education is based on 23 questions (Bloom et al., 2014)). We include two additional questions for the Italian case. The first addresses the SPs ability in fund raising activities. The second is specific to ICT adoption in schools. To ease comparability with cross-country data, we exclude these two specific questions from the calculation of our main index of managerial practices.
} 
selection criteria for students, type of administrative procedures needed for hiring teachers and to increase the number of students.

We collected our data on managerial practices during the period from February to May 2011, with a team of five analysts and two managers that were adequately trained and monitored by the international WMS team. During the training period the team was first prepared to the principles and techniques of the WMS project, then a series of pilot interviews were conducted to familiarize with interview techniques, the questionnaire and the scoring grid. Most importantly, a very large fraction (about half) of the interviews subsequently conducted by the analysts were double scored by the managers or by another analyst. In order to reduce difference in scoring across analysts, some of the interviews were jointly scored by the whole team. The final sample is representative of the population of Italian upper secondary schools. ${ }^{18}$

\subsection{How do managerial practices affect students' outcomes?}

Education scholars recognize an important but often indirect role of the SPs through their influence on teachers. Schools are complex organizations, and SPs are seen as the leaders who set the conditions through which teachers make a more direct impact on students' performance. That is, their contribution to students learning is done by shaping the conditions and climate in which teaching and learning occur. A notable advantage of the WMS tool is that it enables to distinguish the specific channels identified by the literature through which SPs affect students' outcomes. We next describe such channels, how they relate to the measures of practices obtained through the WMS and discuss how they are likely to play out in the Italian institutional environment.

The quality of teachers is considered as one of the primary channels (Hanushek and Rivkin, 2006). The degree of autonomy in the recruitment of new staff and dismissal of the existing one varies by country, since collective bargaining agreements may prevent principals from engaging in firing/hiring low/high performing teachers. ${ }^{19}$ The six questions on the WMS survey section on incentives and human resource management (see the People section, Table A2) ask if rewards or punishments are awarded as a consequence of welldefined and monitored individual achievements and how the school actively controls the number and types of teachers, staff and leadership needed to meet goals. In terms of

\footnotetext{
${ }^{18}$ In Appendix B we explain in detail the selection of the sample, the response rates and we show that there are no significant differences in terms of observable characteristics between the principals/schools that granted the interview and those who refused to participate.

${ }^{19}$ The schooling system is largely dominated by the public sector and collective bargaining agreements are usually binding in most countries. See Loeb, Kalogrides, and Béteille (2012) and Bloom et al. (2012, 2014).
} 
hirings and firings and wage determination, Italian SPs have very limited autonomy since both teachers' allocation and salaries are set at the central level. The WMS survey by design measures actual practices rather than the intrinsic ability of the SP and this implies that institutional constraints will impact on the quality of the managerial practices adopted and on the score obtained by the SPs. Thus, we expect all Italian SPs to obtain low scores in this area of management, while differences across Italian SPs would reflect their ability to apply more informal rather than formal incentives to both select and incentivate teachers and staff.

A second channel focuses on the role of SPs in promoting the introduction of organizational innovations that enable teachers to work more effectively. Indeed, Italian SPs have certainly some discretion in designing the organizational structure of the school they lead, and the impact of institutional constraints on the managerial practices adopted is lower that for human resource management. The set of questions included in both the Targets and Monitoring areas of the WMS focus on these issues. In details, the Targets section of the survey examines mainly the type of targets set by the school in terms of students outcomes. As also stressed by Branch, Hanushek, and Rivkin (2012), public sector CEOs in general and, thus, also SPs, do not necessarily have a well-defined objective function. This is certainly the case for Italian SPs, since they do not have any direct incentive to maximize schools test results and, even at aggregate school level, test results are not made public. The five questions on Monitoring included in our survey focus on the tracking of school performance, reviewing performance with teachers and staff and acting accordingly (e.g., making sure that, if a problem is identified, the appropriate actions to solve it are adopted). It also includes questions on whether school performance data are regularly tracked, reviewed with appropriate frequency, and communicated to the staff (see Table A2 for details).

Organizational innovations also include specific activities that facilitate and improve the quality of teaching and learning. These are also called by education scholars instructional leadership activities (Robinson, Lloyd, and Rowe, 2008; Grissom and Loeb, 2011) and the WMS section on Operations is the one that best identifies these practices. It includes four questions that focus on how the SP deals with different aspects of instructional planning process designed in a school. The main ones are the alignment of instructional strategies across teachers, the capacity to meet specific student needs and how the school provides information and connects students and parents with adequate resources to support students learning. In order to obtain a high score in this area the SP has to specify that when implementing these managerial practices she/he makes use of data and of comprehensive 
monitoring. For example, if we focus on the fourth question (see "Adopting Educational Best Practices" in Table A2), the maximum score is obtained by SPs that provide the school staff with specific opportunities to collaborate and share best practice techniques and also supports their monitored implementation in the classroom, while the minimum is obtained when SP answers reveal only minimal understanding or monitoring of improved practices and learning techniques.

Fourth, motivation of the teaching staff, or transformational leadership, is also considered an important aspect of the SP work and consists of "...the ability of some leaders...to engage with staff in ways that inspired them to new levels of energy, commitment, and moral purpose." (Robinson, Lloyd, and Rowe, 2008, p. 639). The WMS questions on Leadership capture some of these aspects. In general, they are aimed to capture something that is difficult to measure, that is, all activities that SPs perform to informally stimulate/incentivize teachers' work. They also ask whether the SP have clearly identified roles and responsibilities within the school and if there is any internal formal accountability system in place.

Finally, there are other possible paths through which SPs may affect students' outcomes that are not directly captured by the WMS questions. ${ }^{20}$ In particular, SPs may play an important role in determining students' discipline and/or in allocating teachers and students more or less effectively across classes, two activities that are identified by the literature as affecting students' performance. For example, in Lazear (2001) more discipline is usually associated with less disruptions and better students' results, and it represents an important factor to explain the better outcomes obtained by Catholic schools students. Second, consider a setting in which the SPs objective function is to maximize the overall school test score results and the way students are allocated to teachers is a choice variable of the principals, who may assign teachers to students in a way that maximizes average students' performance in the school, i.e. better teachers to a more 'difficult' pool of students. In this case, we should still observe effects of managerial practices on students' performance. Indeed, even if these factors are not specifically measured by the WMS questions, they are nevertheless indirectly captured by them. Both discipline and an efficient allocation of teachers across classes can only be implemented in a well-organized and monitored environment, since it involves guidelines and rules and the monitoring of students' behavior.

\footnotetext{
${ }^{20}$ For more on this see Hallinger and Heck (1998).
} 


\section{Cross country comparisons}

In addition to Italy, the same survey on the education sector has been previously run in Canada, Germany, Sweden, the UK and the US (Bloom et al., 2012, 2014). In this section we compare the measures of managerial practices across such countries. Given the standardized data collection process, the indicators are in fact fully comparable across countries. Given that the econometric analysis of the effects of managerial practices on students' outcomes will be performed for Italy, the only country for which we have students' outcomes data, in what follows we benchmark the discussion on this country.

Cross country differences in the quality of managerial practices can stem from two main sources. First, as seen above managerial practices are clearly influenced by institutional constraints, especially by school legislation and regulations regarding the employment contracts in the public sector. There is indeed a large degree of cross-country heterogeneity in autonomy and accountability of SPs (Pont et al., 2008). For example, in terms of hirings and firings and wage determination, the countries in our sample can be divided into three groups: in the US and the UK SPs have a large degree of autonomy, in Sweden and Canada they have a good degree of autonomy but are subject to some restrictions, particularly on the firing side, and in Germany and Italy they have very limited autonomy. In particular, in Italy teachers are allocated at the central level and cannot be removed by SPs. This will impact on the quality of the managerial practices adopted by the SPs. An institutional framework that greatly constraints human resource management therefore generates low scores in such areas, independently from the intrinsic ability of the principals. A second possibility is that managerial practices are on average (say) of lower quality in a certain country because SPs are intrinsically less capable, depending both on the selection process and on training. It is important to shed light on the relative weight of these possible sources of heterogeneity. The policy implications for improving managerial practices are in fact very different depending on the answer to this question. In the first case, it is to review the institutional framework within which SPs operate. In the second, one should question the selection and training process of SPs.

We begin the analysis with the overall indicator of the quality of managerial practices, Management, obtained as the average of all the questions and reported in Figure 1. With an average of 2.01, the managerial skills of Italian school leaders are significantly lower than those of other countries. The British SPs achieve the highest score, just below 3, followed by Sweden (2.79), Canada (2.80), the US (2.74) and Germany (2.56).

In addition to the average, it is useful to analyze its distribution to evaluate the hetero- 
geneity of managerial skills of the SPs within each country. To explore this aspect, following Bloom et al. $(2012,2014)$, in Figure 2 we report the distribution of the variable for each country. In Italy it is highly concentrated on low values: a significant proportion of Italian SPs implement low-quality management practices. In contrast, in other countries the distribution indicates a significantly higher "minimum" level of management skills, with few SPs with values less than 2, especially in the case of Sweden and Great Britain. Table 1 reveals a similar trend in terms of percentiles. Italy displays the highest interquartile range: the ratio between the ninetieth and the tenth percentile is equal to 1.98 against an average value for all the other countries of approximately 1.5. This is consistent with the idea that in this country there is little control in establishing a minimum level of managerial ability to become a SP.

One way to determine the relative importance of institutional constraints vis-a-vis intrinsic differences in ability is to analyze the results of the survey for the individual subsections. The basic idea is that institutional constraints are likely to be differently binding for different areas of school management. For example, as argued above, there are substantial differences in the constraints in the hiring/firing process of teachers across countries. On the contrary, in all countries there is ample autonomy in terms of monitoring and organization of school processes. If differences in institutional constraints are a major driver of the Italian low performance, we should find that this is mostly concentrated in the areas in which such constraints are more binding.

When we consider the five macro indicators of managerial practices described in the previous section, we find that Italy ranks last in all of them. Moreover, the distance from the other countries tend to be similar across areas. This is a first indication of the fact that the differences in managerial practices cannot be simply attributed to the institutional setting in which SPs operate. This indication is confirmed by a more disaggregated analysis. We take each one of the questions and assign a score from 1 (low) to 3 (high) measuring the degree of institutional constraints. ${ }^{21}$ We then correlate the degree of constraints with the delay of Italy with respect to the other countries. Contrary to the institutional constraints assumption, we find a negative correlation, meaning that the distance between Italy and other countries is higher in areas where SPs have a greater degree of freedom. We reach a similar conclusion when comparing public to private schools within country: we do not find that SPs in private schools do relatively better in activities in which the institutional constraints are more stringent for public schools.

\footnotetext{
${ }^{21}$ To save on space, here we only report the main results, referring the interested reader to the Appendix A and Table A1 for all the details.
} 
All in all, this section indicates that Italian SPs score substantially below those of the other five countries in terms of managerial practices. Moreover, such delay cannot be explained simply by differences in the constraints that SPs face in their activities. Rather, they can be attributed to an overall lower quality of managerial practices, due in particular to a large share of SPs with very low scores. This signals that, to improve the managerial quality of Italian SPs, reforming the institutional setting granting schools more autonomy will not be enough: it will also be important to devote specific attention to the selection and training process of SPs.

\section{Students' performance measures and additional individual- level data}

Our second source of data is the database provided by the National Institute for the Evaluation of the Educational System of Instruction and Training (INVALSI henceforth), a government agency that carries out a yearly evaluation of students attainment in both Mathematics and Language. The INVALSI standardized tests are compulsory for all Italian schools and students, both public and private, attending specific grades of schooling. In our analysis we focus on the 2010-11 school-year data for tenth grade upper secondary school students. ${ }^{22}$

The 2010-11 was the first school year that these evaluation tests were performed by upper secondary school students. ${ }^{23}$ For this reason, the Language test has been intentionally designed by INVALSI to be easier than normal while, conversely, the Math test has been left to a standard level of difficulty in order to precisely measure all skill levels, including the highest. ${ }^{24}$ Thus, we exclude the Language test data from our analysis and focus only on the normalized test scores values in Mathematics, obtained as percentage of right answers.

The INVALSI questionnaire is also designed in order to collect detailed information about the student's background and family characteristics. ${ }^{25}$ In our analysis we include the

\footnotetext{
${ }^{22}$ Tests are carried out also by students attending the second and fifth grade (in primary schools) and the sixth and eighth grade (in lower secondary). The Italian school system starts at age six with five years of primary school (grades 1 to 5) followed by three years of lower secondary school (grades 6 to 8). Upper secondary education lasts three to five years depending on the type of school chosen.

${ }^{23}$ Even if the Italian high school system is based on three main differentiated curricula (Vocational, Technical and Lyceum) both the Language and Mathematics tests and their administration procedures were identical for all schools and students. In fact, similarly to the OECD PISA, the INVALSI standardized tests aim to measure how far students have acquired some of the knowledge and skills essential for full participation in the knowledge society.

${ }^{24}$ On this see INVALSI (2011), p.25. Language and Mathematics test scores are very differently distributed and only math is distributed along the whole scale of skill.

${ }^{25}$ Information is collected through a "Family Questionnaire" sent to each family before the test, a "Student
} 
following additional students demographic information: gender, citizenship (native, first and second generation immigrant students), grade retention and an index of socioeconomic background. ${ }^{26}$ The latter is calculated based on the parents' occupational status, their educational attainment levels and different measures of household possessions including cultural possessions such as home educational resources and the number of books. This ESCS index for students socioeconomic background is analogous to the same one computed by OECD for the PISA test. The individual scores of this index are obtained by a principal component analysis, with normalized zero mean and unit standard deviation. ${ }^{27}$

Our WMS survey dataset on principals and schools is therefore matched to the INVALSI dataset through an anonymous school identifier. Table 2 sums up the major characteristics of these additional variables for our overall sample. We find that our sample is not significantly different from the INVALSI 10th grade students census one (data in brackets) in terms of observable characteristics. As expected, the figure for female students is $50 \%$, while the percent of correct answers our sample students get on the math test is 48.59 (it is 48 for census data). Moreover, first and second generation immigrant students represent respectively, $6 \%(5.2 \%)$ and $2 \%(2.4 \%)$ of our sample and the percentage of retained students is $22 \%(22 \%){ }^{28}$ Thus, only the presence of first generation immigrant students is somewhat oversampled. Finally, both the mean value and the standard deviation of the ESCS index confirm that, even in terms of students socio-economic background, our sample is not biased.

Finally, in order to control for other catchment area characteristics we also use additional data at municipal level provided by the Italian National Institute of Statistics (ISTAT). ${ }^{29}$ This dataset enables us to construct a proxy for the wealth level of the school catchment area using data on per capita bank deposit, and to control whether a school is located in densely, intermediate density or sparsely populated areas. As expected for grade 10 students, data in Table 2 show that most upper secondary schools are located in densely populated areas,

Questionnaire" filled by each student the first day of the test and, finally a students general information part compiled from school administrative staff.

${ }^{26}$ More precisely, first generation are students born abroad of foreign-born parents, while second generation students are native-born children of foreign-born parents. Our dummy retained student is equal to one when if the student is older than "regular" students, that is, if, at the end of 2011, he/she is older than 16 years old.

${ }^{27}$ They are the scores for the first principal component. The index is calculated considering the whole sample of tenth grade upper secondary school Italian students. See also INVALSI (2011) and OECD (2012) for details.

${ }^{28}$ Note that this retained students dummy includes also non-native students that are allocated to a lower grade on the basis of their language skills and not on the basis of a simple age rule.

${ }^{29}$ These data are provided by ISTAT in the Atlante statistico dei comuni dataset. 
with only $11 \%$ located in rural areas.

\section{Empirical framework and identification}

We study the effects of managerial practices on students' outcomes using a simple regression setting of the form:

$$
y_{i j}=\alpha+\beta \text { Manag }_{j}+\gamma X_{i j}+\delta Z_{j}+v_{i j}
$$

where $y_{i j}$ is an indicator of performance of student $i$ attending school $j$, Manag $_{j}$ is the indicator of managerial quality for school $j, X_{i j}$ is a set of individual students' controls, $Z_{j}$ are school, SP and local controls.

Our basic analysis will use OLS regressions. The main problem with this approach is the potential endogeneity of managerial practices. In particular, three selection issues can invalidate the causal interpretation of the $\beta$ coefficient. First, it might be that more capable SPs self select into schools with better students; second, better teachers might self-select in schools with better managerial practices; third, better students might also do so. We take particular care in addressing the endogeneity concerns.

In terms of SPs self-selection, our data include an extremely rich set of students, SPs and schools controls. We include in all regressions controls for socio-economic characteristics of the students and of the municipality where the school is located, for school types, for SPs demographics. This allows us to control for the most likely sources of endogeneity. For example, assume that more capable SPs self-select into the more prestigious "liceo classico", where students tend to perform better in the standardized test. This is not a problem in our setting. In fact, given that we include a full set of school type dummies, we only use within school type variability of students outcomes to identify the effects of managerial capabilities on students' achievements. The same occurs if one is concerned that more capable SPs self-select in schools with students from high income families, as we control for students socioeconomic background.

A second reasons that reduces endogeneity concerns is related to the process through which principals are assigned to schools. For their first assignment, school principals express up to three preferences, choosing among the vacant schools. Afterwards, they can ask to be transferred to a different school. Actual assignments are made by the Regional School Authority (RSA). There is no formal procedure that the RSA must follow. In practice, RSA try to accommodate SPs requests, but have to fill in the positions for the schools that were not chosen by any principal. 
Selection issues are unlikely to be at play for SPs that are assigned a school that they have signalled as preferred. In general, the Italian school accountability system does not promote any obvious self-selection process of better SPs in schools with higher ability students. First, there is no reward explicitly linked to students' outcomes in standardized tests. Formal selfevaluation procedures are just starting to be introduced in the Italian system and students' achievements and results cannot be used for external evaluation and are not even made public at the school level. Second, SP salaries are set by nationwide schedules and depend almost completely on experience and seniority. Indeed, the main concern of the SP is school attractiveness, as the number of students determines the budget, the number of professors etc. that the SP administrates. If enrollment falls below a certain threshold, the school may be merged with another one. Third, even if SPs would actually want to manage schools with better performing students, there is little reason to believe that assignments reflect managerial abilities. In fact, informal conversations with RSA representatives suggest that assignments are based mostly on seniority, i.e., more senior SPs are more likely to get their preferred school. Given that we control for seniority, and that seniority does not seem to be a major determinant of managerial ability, even in this case endogeneity concerns are not likely to be crucial. Finally, given the generally low mobility rate of Italian workers, a major issue in the school choice decision is likely to be distance from residence. ${ }^{30}$

Selection problems might be more relevant for the schools that are not chosen by the SP but assigned by the RSA. These might indeed be exceptionally "difficult" schools, for which the RSA exerts some informal pressure on SPs that have signalled to be particularly social responsible to take up those schools. In this case, the RSA might try to allocate more capable SPs to more problematic schools. To control for this possibility, in the survey we asked SPs if they were assigned to a school they requested, i.e., they have chosen. In 80 percent of cases this is indeed the case. We use this as our basic sample, excluding SPs that manage a school they did not request. ${ }^{31}$

Although we argue that the selection mechanism is unlikely to give rise to serious endogeneity concerns, we cannot completely rule out this possibility. We will also perform a set of IV regressions and focus on the institutional changes that should determine exogenous

\footnotetext{
${ }^{30}$ There is widespread evidence of low willingness to move in the Italian labor market. For example, according to a 1995 survey of the National Institute of Statistics, more than $40 \%$ of unemployed workers were unwilling to take a job outside the municipality of residence and only $22 \%$ were ready to move anywhere Faini, Galli, and Rossi (1996). Specific evidence on teachers' mobility can be found in Barbieri, Rossetti, and Sestito (2011).

${ }^{31}$ In terms of the sample characteristics Table 3 shows that this selection does not cause any significant change: for each variable, both sample averages and standard deviations are almost identical to those reported in Table 2 for the full sample case.
} 
shifts in SPs managerial abilities. Since 2000, Italian schools have enjoyed greater organizational autonomy and SPs became also school managers with full responsibility over the school budget. Before that, the main role of SPs was that of "instructional leader" rather than of manager and the national competition to acquire the status of upper secondary SP was school-type specific, that is, one could not transfer from Lyceums to a Vocational school. However, it was only in 2004 that a new national competition was introduced to become SP, while the newly selected SPs have been appointed from 2006 onward. Thus, in principle, managerial skills and specific training in human resource management were required to become SP and we can exploit this institutional change in our identification strategy.

A second source of selection is that teachers might choose to move to better managed schools. However, this is not a problem in our framework: rather, it is exactly a key channel through which good managerial practices should operate. Indeed, a SP implementing good managerial practices can affect teachers behavior both through a selection and a treatment effect. Both of these channel are measured by our survey. For example, there are a series of questions on attracting/retaining talents: a good practice is one that operates along this dimension. The same is true in terms of motivating and monitoring behavior: a good practice is one that stimulate effort from teachers. Attracting and retaining better teachers by offering them a well-functioning working environment is one of the key effects of good managerial practices.

A more serious concern is that the best students might choose to attend schools with better managerial practices. Again, this concern is alleviated by the large set of individual controls we insert in the regressions. In addition, we will address this concerns in Section 8 exploiting the heterogeneity of students by comparing the results for isolated school vs. those with other schools in competition within the school catchment area.

\section{$7 \quad$ Main results}

To investigate the relationship between SP's managerial skills and students' outcomes we estimate a standard education production function where student test performance in mathematics is modeled as a function of SP managerial skills and a set of additional variables that control for personal characteristics (age, gender and tenure in school), students' characteristics (gender, socio-economic background, native/I or II generation immigrants, grade retention), school and teachers characteristics (size, type, competition, private/public, teachers turnover) and catchment area characteristics (urbanization, per capita bank deposit and 
regional dummies). We first discuss the results for the management variables and then move on to the other controls.

\subsection{Management variables}

We set the scene in Table 4 where we show the OLS results when we alternatively use our six different measures of managerial practices, in addition to the full set of controls. This sample includes 27775 students that are attending schools with principals that lead a school they requested/chosen. ${ }^{32}$ Robust standard errors, clustered at principal/school level, are reported in parenthesis. We start in column 1 with our main SP's management practices indicator that represents an overall measure of managerial ability. Results on Management implies that, holding all the other independent variables constant, Italian SPs management practices play a positive role for students' performance. In particular, since our dependent variable ranges from 0 to 100, the estimated coefficient value implies that a one unit increase in our management score is expected to increase our average students test score results by more than 2 points, on a mean of 49 out of 100 . To give a sense of the magnitude of a unit increase in management, Table 3 shows that the standard deviation of this variable is around .5. More interesting, a unit increase in our management score almost corresponds to the difference between the mean score of all Italian SPs (2.01) and the mean score obtained by the UK SPs sample (2.98). This meas that, if Italian SPs would have on average the same managerial ability of the UK SPs, students's test scores would increase by around $4.6 \%$.

In columns 2 to 6 we investigate the effects of the various dimensions of managerial practices. Column 2 focuses on Leadership, the area of management identified by the education literature as an important channel through which SPs may influence teachers behaviour and, thus, students' outcomes. In general, leadership skills are described as the ability of some SPs to engage with the school's staff in ways that motivate them to high levels of efforts and commitment. As discussed above, questions on Leadership ask whether the SP have clearly identified roles and responsibilities within the school and if there is any internal formal accountability system in place. Our analysis confirms that Leadership represents an important area of management for SPs: the estimated coefficient is 2.72, significant at the $5 \%$ level.

A second area of management that seems to matter for students' outcome is monitoring

\footnotetext{
${ }^{32}$ We report specific descriptive statistics for the sample used in regressions in Table 3. Note that averages and standard deviations are very similar to those reported in Table 2 for the overall sample, that also includes SPs that have not chosen the school.
} 
of school processes. Column 4 suggests that tracking of school performance, reviewing performance with teachers and staff, and the remaining specific managerial skills identified by Monitoring implies a positive and significant coefficient.

Conversely, the remaining individual managerial practices deliver less precise indications and all coefficients are positive but not statistically significant. Column 3 includes our measures on Operations, a management practice which concerns the standardization of the teaching process, the customization of teaching, the use of data in school management and the adoption of best practices. As discussed in Subsection 3.2, compared to other areas of management considered, this is perhaps the one that is closest to the so called instructional leadership whose importance in the education literature is highlighted in several works. Column 5 includes results on Targets that examines mainly the type of targets set by the school in terms of students' outcomes, their realism and whether they are given consistently throughout the school organization. Compared to other countries, Targets represents the individual management area where Italian SPs obtain both the lowest score (1.77) and the largest gap with the best performer country (UK, 2.97 points). Our last management area includes People (column 6) or the incentives section that focus on promotion criteria, pay and bonuses, and fixing or firing bad performers. This is an area in which institutional constraints are likely to be particularly binding, so it is not surprising to find the lowest coefficient of all areas.

Finally, since the different domains might also be correlated, for each area of management we have also replicated the previous analysis introducing an additional control calculated as the average of the remaining managerial domains. ${ }^{33}$ Results, available upon request, fully confirm the reported findings.

\subsection{Other controls}

We now turn our attention to examining the results obtained on our additional regressors. In general, we do hardly observe any difference on each of these regressors among our six different specifications. First of all, we focus on three additional SP characteristics, that is, age, gender (women make up 37\% of our sample) and tenure in school. Previous studies that quantitatively examine the role of school leaders show mixed evidence regarding the

\footnotetext{
${ }^{33}$ In particular, we may have complementarity across managerial practices areas: i.e. the institutional constraints on hiring/firing might therefore affect also the Italian SPs incentives to do monitoring. However, this is not necessarily the case. For example, the cross country PISA survey data on school leadership do not show any obvious complementarity, with countries ranking low on SPs autonomy in hiring and firing, and high on teachers monitoring.
} 
relationship between school performance and principal characteristics. ${ }^{34}$ Principal's age is important since, as said above, anecdotal evidence suggests that the more prestigious schools are assigned by the RSA to older SPs as a sort of end of career benefit. Thus, even if we are focusing on the specific sample of SPs that have chosen the school where they operate, it is still possible that younger SPs end up in less prestigious ones. Tenure should control for the possibility that the overall impact of SPs on a specific school increases over time as it takes time for SPs to implement new policies. Thus, without this control our management variables could also capture variation in SPs quality related to differences in length of tenure. Overall, it seems difficult to identify specific SPs demographic characteristics that are good or bad in terms of student performance. In fact, additional principal characteristics, including age, do not seem to matter for students educational outcomes.

Results found in Table 4 for the remaining indicators are largely consistent with the literature. One important exception is the private schools dummy that shows a negative and significant coefficient, implying that private school students' performance on standardized tests is worse than that of public Italian school students. This should come as no surprise since, unlike most industrialized countries, private schooling in Italy is associated with poorer rather than better outcomes. As suggested by Brunello and Rocco (2008), one of the main reasons is that the large part of Italian private schools focus more on the recovery of less able students than on across the board high quality education. That is, Italian families often choose private, including religious, schools, to obtain degrees from less demanding private institutions. ${ }^{35}$

Second, as found in previous studies on the Italian case, our results on schools characteristics reveal a significant role for the educational track. Italian upper secondary school tracking is determined by the presence of differentiated curricula rather than by a formal assignment process to academic or vocational courses depending on students' past performance or on alternative selection processes. Therefore, Italian students choose schools that specialize in each of the three main curricula: Lyceum, Technical and Vocational. ${ }^{36}$ In particular, the vocational/academic intensity is at its lowest/highest level in the Lyceum (with

\footnotetext{
${ }^{34}$ In particular, studies that use the value added approach often find that the vast majority of variation in educator (both principals and teachers) quality cannot be explained by their observed characteristics. On this see Li (2012).

${ }^{35}$ See for example OECD (2012). OECD PISA data show that in 16 OECD countries and 13 partner countries and economies, students in privately managed schools tend to perform better than students in publicly managed schools, but Italy is one of the very few exceptions.

${ }^{36}$ Due to this mechanism, in addition to their cognitive abilities (test scores, grade repetition, previous marks), Italian students sorting is also significantly driven by the family background. See Brunello and Checchi (2007). Recent evidence shows that the learning divide due to family background originates in the early stages of the schooling process, in particular in lower secondary schools. See De Simone (2013).
} 
almost no vocational component) and at its highest/lowest level in Vocational schools. In between these two curricula there is the curriculum offered by Technical schools. Moreover, only Vocational schools can last for 3 rather than 5 years, even if graduates from all three school types, after five years, may continue to tertiary education. In sum, there are significant differences in terms of programs and curricula as well as in the average test scores of students across the three types of schools.

Among additional type of school controls, we introduce another dummy variable, "Istituto Superiore", that identifies if a school offers different types of curricula. ${ }^{37}$ The coefficient is always negative and significant. This could be an indication that this type of schools, that constitute $37 \%$ of our sample, are more complex and difficult to manage and this may affect students' outcomes. ${ }^{38}$ Further, we also find that both school size and school competition do not significantly affect students' test results. ${ }^{39}$ We finally include a measure of teacher's turnover. Italian principals have almost no control over new hires or teachers' transfers thus we only have voluntary transitions. This variable too is not significant.

Third, we presents estimates of students' characteristics. The results obtained are very much consistent with the literature. In general, cross country analysis shows that mathematics gender gaps results in favor of boys are rather unstable and rapidly evolving, with countries with a more gender-equal culture often showing a nil or even reversed gender gap. ${ }^{40}$ Our analysis confirms past results on Italian data with the presence of a significant "gender gap" in terms of boys outperforming girls in mathematics.

As expected, the index of socioeconomic background is positively strongly associated with student achievement. Although it does not include any specific data on family income, this variable is created on the basis of the occupational and educational level of the student's parents, home educational and cultural resources. Further, estimates confirm that children of immigrants face important gaps in math, with first-generation immigrants representing the most disadvantaged group. Note that significant immigration flows in Italy only started in the Nineties but, from then on, have risen sharply over the last decade and almost $8 \%$ of students in our sample are first or second generation immigrants. We also include a dummy that captures if a student is repeating the grade or if she/he is a retained students and find, as expected, a negative and significant coefficient.

\footnotetext{
${ }^{37}$ In this case, the school type is identified at class rather than school level.

${ }^{38}$ These schools include combinations of different types of curricula and are usually located in rural areas.

${ }^{39}$ Schools (and teachers) facing a direct competition may exert more influence and put more efforts to improve students outcomes, while Böhlmark, Grönqvist, and Vlachos (2012) suggest that principals in smaller schools have a larger influence on students' academic results.

${ }^{40}$ Guiso et al. (2008). For example, OECD PISA results report some male advantage in all rounds although not in all countries. See Eurydice (2010).
} 
In terms of catchment area characteristics, we construct three dummies for whether a school is located in densely populated, intermediate density or sparsely populated areas. None of this measures significantly affect math test scores. Conversely, the log of per capita bank deposit, a proxy for the wealth level of the school catchment area, is always positive and significant. We also include regional dummies. In fact, previous studies show that geographical location is an important determinant of Italian students test scores, with students in the North-East area usually outperforming the others, and those from the South being substantially behind (Cipollone, Montanaro, and Sestito, 2010; Bratti, Checchi, and Filippin, 2007). Results (available upon request) confirm this pattern. Moreover, regional dummies are important also because they enable us to control for possible local differences in principal's allocation rules. In fact, as said above, since SPs' actual assignments are made by each Regional School Authority, both formal and informal assignment rules differ across the different areas and our dummies should capture at least part of this sorting.

\section{Robustness and Extensions}

\subsection{Endogeneity and Sorting}

In this section we perform a set of robustness checks of the basic results discussed above. We first address selection issues. If SPs' managerial skills are not orthogonal to the unobserved component of students' test scores, OLS results are clearly biased. Ex-ante, the direction of the bias could go either way. On one side, better SPs might be able to choose schools with better students. This would imply an upward bias of the OLS regressions. On the other, the informal pressure exerted by the RSA on good SPs to take up "difficult" schools may had an impact also on those SPs who declared in our survey to have chosen the school. In this case, OLS estimates would suffer from a downward bias.

To control for the possible endogeneity of managerial practices we exploit the new national competition introduced in 2006 to become SP. The competition was based on an exam that included testing specifically for managerial skills: that is, the SPs appointed from 2006 onward might have had better managerial abilities than those selected before the reform. We therefore use a dummy equal to 1 for SP appointed after 2006 as an instrument for management. The rank condition requires that such reform had an impact on the managerial capabilities of SPs selected after the reform was implemented. The exclusion restriction requires that being selected after the reform does not systematically correlate with the students' outcomes of the schools such SPs are assigned to (again, conditional on the rich set of observables, as well as on SPs characteristics, such as age, clearly correlated 
with the instruments). We deem both assumptions as reasonable.

Using this model specification, results on the intent to treat regression and first-stage regression are as expected. The former results show a significant and positive relationship between post-2006 SPs and students outcomes. The idea is that this relationship reflects the effect of the new selection rules on management and first stage results support this hypothesis, with the positive and significant sign of our instrumental variable also on the first stage. To save on space we do not include these results here but only show in Table 4 the second stage results when we alternatively include our six different proxies of managerial practices.

The point estimates of the IV regression reported in Table 5 suggest that, if anything, the OLS largely underestimate the importance of managerial practices. The coefficients on Management, Monitoring and Targets are all significant and larger than the OLS estimates. This is exactly what would result from a process of nonrandom allocation between good SPs and schools with low performing students as previously described. However, we stress that these results need to be interpreted with caution. In fact, the Kleibergen-Paap F statistic signals weak instruments problems. In general, as a rule of thumb, to confirm that our instruments are relevant we should find a first-stage F-statistic larger than ten, but in all columns we find significantly lower values. We therefore create confidence intervals robust to weak instruments that we include among results. For most management areas the Anderson-Rubin AR confidence intervals are conclusive in suggesting a positive effect of management on students results, even if we are still unable to predict the magnitude of the effect, as the interval is very large. Two exceptions are Leadership and Operations that show a disjoint pair of confidence intervals. We take these results as corroborating the OLS ones of a positive effect of managerial practices on students' outcomes, but, given the weak instrument problem, acknowledge that the point estimate have to be taken with a grain of salt.

Our instrumental variable approach is mainly aimed at solving endogeneity issues arising from SPs self-selection. As pointed out in Section 6, a second concern is that the best students might choose to attend schools with better managerial practices. A simple descriptive evidence shows that the average quality of managerial practices adopted in schools attended by disadvantaged students is almost identical to that observed in high socioeconomic background schools (respectively, 2.01 and 2.09). Second, the characteristics of the Italian upper secondary school system should help to mitigate this problem. Unlike primary or lower secondary schools, in Italy the main students sorting mechanism is across the dif- 
ferent types of schools and curricula rather than different schools characteristics, including SPs. We control for the type of school in our regressions, and thus we still have to control for the within type of school students sorting. Since this sorting process arises mostly in densely populated areas, where families can choose between different schools offering the same curriculum, we have run separate regressions for students attending schools that do and do not have other schools in competition within 30 minutes driving distance. The rationale for this exercise is that, for the isolated schools sample, families have no choice and, if endogenous sorting were driving our results, we would expect to find that managerial practices matter more for the sub-sample of schools in competition. Results in Panel A of Table 6 show the opposite: the effect of good managerial practices is larger (a coefficient of 4.97 vs 2.67) in the isolated schools sample. In sum, this evidence rules out this alternative interpretation about the positive relation between test scores and SP, and support the causal interpretation of our OLS estimates.

\subsection{Other Robustness Checks}

As a first robustness check we focus on the important issue of the role of principals managerial practices when serving different types of students. As stressed in Branch, Hanushek, and Rivkin (2012), case studies and anecdotal accounts find that the effect of a good SP seems most apparent when serving disadvantaged populations, but other studies assume that some specific school policies affect the elite students more than the disadvantaged ones. ${ }^{41} \mathrm{We}$ therefore run separate regressions on two sub-samples defined on the basis of our school average socio-economic background index: since this indicator has normalized zero mean and unit standard deviation, we split the low and high socio-economic background samples according to this index being below or above zero. When we test the possibility of effect heterogeneity, results in Panel B of Table 6 indicate a larger effect of managerial practices for the disadvantaged group.

This result appears also to contradict another possible explanation for a positive correlation between managerial practices and students outcomes, namely, complementary parental investments. In this case, the positive effect of managerial practices may arise if parents invest more in children trained in schools managed by more able SPs. However, it is plausible that only parents from a high socioeconomic background alter investments in their children in response to changes in schooling inputs. If this is the case, our results seem rather to suggest that SPs practices and parental investments might be substitute more

\footnotetext{
${ }^{41}$ For example, this is the case of discipline in Lazear (2001).
} 
than complements. ${ }^{42}$

A potential mechanism influencing our results is also the possibility that SPs adopt different strategies of cheating, thus inflating test scores to attract better students. ${ }^{43}$ For example, SPs may dissuade bad students to show up on the day of the test, they may suggest the correct answers to weak students, or they may directly manipulate students tests to inflate results. Although such behavior may well take place, there are various reasons for ruling out such mechanism in this context. First, there is no built in relation in the way our measures of managerial practices are constructed and possible cheating behavior of SPs. The latter may emerge in a context of high levels of competition between schools to attract better students, or simply in a context of low accountability where moral hazard problems for teachers are possible. The survey questions detailed in Table A2 suggest that there is no obvious relation between such behaviour and the quality of managerial practices. Second, our dataset enable also to identify a representative and random sample of monitored classrooms where external inspectors invigilate students during the test and also help to both compute results and prepare the documentation relative to the test. Existing evidence shows that students in the non-monitored classroom received a more "benevolent" supervision, allowing students' cheating behaviour more easily (Lucifora and Tonello, 2012). Panel C of Table 6 shows the results when we introduce in our basic specification a dummy for the presence of an inspector in the class plus an interaction term between the latter and our measures of managerial quality. Results do not suggest that SPs that adopt better managerial practices tend also to cheat in test scores: the interaction term is never statistically significant, while results for managerial practices are virtually unaltered with respect to those reported in Table 4.

In Table 7 we return to the baseline OLS model and interact our measure of managerial practices with tenure in school, while keeping the remaining controls as in Table 4. School tenure should capture accumulation of skills that are specific to the school environment in which the SP is operating, ranging from organization and motivation of teachers and administrative staff to a general knowledge of the school operations or particular issues related to the school specificity. Results, reported in Table 7, are mixed. First, the effect of managerial skills increases and becomes more significant with respect to the baseline results. Second, the effect of tenure is positive, although it is marginally significant only

\footnotetext{
${ }^{42}$ On this see Datar and Mason (2008). We also split the sample according to parents education with no significant differences for different groups.

${ }^{43}$ See Angrist, Battistin, and Vuri (2014) and Lucifora and Tonello (2012) on cheating in test scores in Italy.
} 
for the dimensions Leadership and Monitoring. The interaction term between managerial practices and school tenure is negative and marginally significant in the same two cases as above. ${ }^{44}$ One possible explanation is that newly appointed SPs do rely relatively more on their managerial skills when they are assigned to a new school, implementing formal managerial practices and methods to gain leadership and accumulate knowledge about the school, while they rely more on informal and less managerially oriented methods when they have accumulated tenure in the school. ${ }^{45}$

As we have discussed above, an important source of variability in terms of managerial practices is given by cohort effects. In fact, for SPs appointed before the reform of year 2000 there was little emphasis on managerial capabilities and more on instructional leadership. These SPs might therefore tend to manage the school relying less on the formal managerial procedures investigated in our survey. For this sample, therefore, this measure might be less telling than for the sample of SPs first appointed after 2000. Moreover, this cohort might be characterized by lower managerial ability but, possibly, be assigned to better schools, as seniority plays a role in the assignment process. In what follows, we further investigate this issue by estimating our baseline OLS model excluding SPs appointed up to year 2000. We expect that for this restricted sample of SPs good managerial practices should matter more for student outcomes. Results reported in Table 8, obtained on a sample of 14060 observations, confirm our a priori expectations: for the sample of SPs that were firstly appointed after 2000, we find a large and statistically significant positive effect for all dimensions of managerial abilities on students' outcomes. The coefficient for the overall managerial index reported in column 1 of Table 8 indicates that an increase in the index by one point increases students' scores by more than 6 points with an increase of about $12 \%$, an effect that is almost 3 times as large as the one found in Table 4 on the sample of SPs that chose the school and including all cohorts of SPs. The effect of management on student outcomes turns positive and statistically significant when we also use other measures of managerial skills. As stressed above, while the effect in the sections Leadership and Monitoring are confirmed, it is interesting to note that an increase by one point in managerial abilities related to People and Targets increases student scores by more than 5 points, suggesting that for this cohort of SPs all dimensions of managerial abilities matter for the good performance of students. Finally we report a positive effect for Operations

\footnotetext{
${ }^{44}$ To capture non linear effects, we also tried a different specification including a quadratic term for school tenure and interacting managerial practices accordingly, results are virtually unchanged.

${ }^{45}$ Indeed, results in the literature on the effect of tenure of SPs on students' outcomes are mixed. See Branch, Hanushek, and Rivkin (2012), Coelli and Green (2012) and Dhuey and Smith (2012) among others.
} 
practices, even if the magnitude of the coefficient is the smallest across dimensions (2.15).

In Section 4, we have stressed the importance of institutional constraints as a factor that may help to explain the observed gap in managerial abilities between Italian SPs and those operating in other countries and we have also classified each single question according to the relevance of such institutional constraints. When institutional constraints are binding, as it is the case in Italy for the the human resource management area, we expect that management scores are more similar across SPs and that SPs activities may be less effective. Conversely, we should expect that managerial practices can make more of a difference in areas where the institutional constraints are less binding. In what follows, we exploit this classification to group the individual questions into three different measures of managerial practices classified as low, medium and high level of institutionally constraint activities, with each managerial practices variables obtained as the mean of the corresponding questions (see Table A1 and Appendix A for details about the classification of each question). Results reported in Table 9 indicate a consistent pattern: managerial practices have a positive and statistically significant effect (about 2.5 points) on students' outcomes only when we consider the index constructed using areas of managerial practices that have low institutional constraints (see column 1), while we observe a positive but not statistically significant effect when we consider the other two indexes in columns 2 and $3 .^{46}$

The identification strategy of the effect of managerial practices adopted in our paper exploits the variability of outcomes across students, but the independent variable of interest only varies across schools, and we have always clustered the standard errors at the school level. As a further check, we supplement our main findings with regressions based on school averages in test scores as the dependent variable, so that we have one observation by school. Other regressors are also obtained as school level averages. We report our results in the first row of Table 10 for the overall managerial index and separately for all different sections of managerial practices. Overall, the results confirm our previous findings: while we do find a positive but not statistically significant effect for our main Management index, and for Operations and Targets, the positive effect for Leadership and Monitoring is confirmed to be statistically significant, with an increase of student test scores that is equal to about 2 points for an increase of 1 point in the respective index of managerial ability.

We further investigate the important issue of what kind of students benefit more from good managerial practices with our school level data. To this aim, we replicate our standard analysis using the level of student test scores at the 10th, 50th and 90th percentile within

\footnotetext{
${ }^{46}$ We run such regressions on the sample of SPs that chose the school used in Table 4 to estimate our baseline model.
} 
each school as dependent variables. Results, which are reported in rows 2 to 4 of Table 10, indicate that, overall, managerial practices affect 10th, 50th or 90th percentiles students in a very similar way. In details, good managerial practices in terms of Leadership and Monitoring do have a positive and statistically significant effect on student outcomes, and such effect is quite similar in size across different parts of the distribution. For example, good managerial practices in Monitoring increase test scores similarly for both the bottom and upper part, respectively low achieving and elite students, of the test scores distribution (with an effect equal to 1.44 and 1.87 respectively). In other words, school level data suggest that good managerial practices shift the distribution of student scores to the right without basically changing its shape. ${ }^{47}$ Consistently, we also find no statistically significant effect of managerial practices on different measures of dispersion of student outcomes, reported at the bottom of Table 10, such as the 90/10 percentile difference or the standard deviation of test scores between students in the same school.

We conclude our regression analysis by considering the effect of managerial practices on a different students' outcome. We run probit regressions in which the dependent variable is equal to one if the student is lagging behind with respect to the age/grade ladder and zero otherwise. Such variable was used in our previous regression as an additional control for student characteristics. Even these results, not included here, show a positive role for SPs' managerial practices: good managerial practices reduce the probability of student retention by 3 percentage points, with an effect that is almost constant across different dimensions of management. ${ }^{48}$

\section{Comparing WMS with OECD PISA}

Since 2006, the OECD includes a section in the PISA (Programme for International Student Assessment) survey that investigates SPs managerial practices. ${ }^{49}$ This data collection system is based on a self-reported measures and it is clearly much simpler (and cheaper) than the one of the WMS. It is therefore interesting to investigate if the two surveys supply comparable information. If this were the case, one could resort to the simpler, cheaper collection method to obtain reliable indicators of managerial practices.

\footnotetext{
${ }^{47}$ Note that this result is not at odds previous evidence of a larger effect for the most disadvantaged students discussed above. These two sets of results are easily reconciled in presence of school segregation phenomena. When "good" and "bad" students tend to clustered in different schools, we may find that SPs activities might be more beneficial in schools where the disadvantaged students tend to attend but, within school, they affect the student's results in a similar way.

${ }^{48}$ The full set of results can be found in Di Liberto, Schivardi, and Sulis (2013)

${ }^{49}$ An analysis on the 2006 data can be found in Pont et al. (2008).
} 
We use the most recent PISA release of 2009 where we identify three indices of managerial practices. The main one is the index of principal leadership (LDRSHP), which captures if principals are active in improving both schools teaching practices and the working environment. The PISA dataset constructs this index as the average of the answers that the SP, or a designate, reports in Q26 of the School Questionnaire on the frequency with which fourteen areas of activities are performed during the school year. The indicator ranges from 1 (never) to 4 (very often). There is therefore a clear difference between what the PISA and the WMS measure. In fact, PISA is a measure of self-reported effort, while in the WMS the interviewer directly assesses the quality of the implemented practices. In addition to the overall indicator, the fourteen specific items can be classified in terms of three of the WMS key areas of management, namely, Leadership, Operations and Monitoring. ${ }^{50}$ This enables us to construct three additional sub-indices to be used in our comparison.

A second PISA variable that can be used as a measure of school management activities is the index of school responsibility for resource allocation (RESPRES). In this case the PISA survey asks to report whether (and/or) 1) principals, 2) teachers, 3) school governing board, 4) regional or local education authority or 5) national education authority has/have responsibility for both human resource management and in deciding on budget allocations within the school. Finally, a third index, calculated as the previous one, refers to the school responsibility for students' curriculum and assessment (RESPCURR). Positive values on these two final indices imply relatively more responsibility for schools than local, regional or national education authorities. The three indices, LDRSHP, RESPRES and RESPCURR are all standardized with (OECD) mean zero and a standard deviation one.

We start by comparing the two main indices, that is, LDRSHP for PISA and Management for WMS for the six countries in our WMS sample. To make the indicators comparable, we use the average values of Q26 items and rescale both the WMS and PISA data into a range from 0 to 1 . Figure 3 reports the average values at the country level. First, note that the PISA indicator is in all cases substantially larger than the WMS one. This is evidence that self reported values might inflate the measure with respect to that based on the assessment of an external reviewer. Second, the two surveys display significant differences even in terms of country ranking: while the UK is the best performer in both datasets, Sweden performs relatively worse in the PISA ranking while the opposite is true for Italy.

\footnotetext{
${ }^{50}$ Leadership includes answers to sub-questions (a), (k) and (l); Operations items (b), (c), (e), (h), (j) and (m); Monitoring (d), (f), (g) and (i). The last question/item (n), explores if the SP takes over lessons from absent teachers, an issue which is not explicitly covered by our WMS survey. Note that we also have replicated the analysis using a new variable of PISA-Management that exclude this item, and results are almost identical.
} 
In Figure 4 we report the distribution of both our WMS management measure (in bright-yellow) and the PISA main index (in darker-green). This figure clearly shows that, unlike the WMS data, the PISA index distribution is, for all countries, concentrated on high values. In particular, for the UK and Italy (the best and the worst performers according to the WMS) the two distribution seldom overlap. We interpret this as a further indication that the PISA data suffer self-assessment bias and/or that the frequency with which certain activities are performed has little to tell about the quality of the managerial practices. For example, the LDRSHP is based on the frequency with which the principal is involved in a series of organizational activities: about $75 \%$ of the 3026 principals/schools interviewed in the PISA six country sample rates her/his overall activity between 3 and 4 (recall that the range is $1-4$ ), the remaining $25 \%$ between 2 and 3 , while not a one reports a value between 1 and 2. We have also used an alternative WMS management indicator that takes into account only the three areas of management (Leadership, Operations and Monitoring) included in the LDRSHP index provided by PISA. Figure 5 shows that this hardly changes the picture.

We next move on to correlate students' achievements with the indicators of managerial practices, following the same scheme as before. The dependent variable is the individual students PISA test scores in mathematics, while the set of regressors is chosen in order to replicate our baseline specification of Table $4 .^{51}$ The only exceptions are the SPs demographic variables, not included in the PISA dataset.

Table 11 shows the OLS results on the Italian sample. With more than 1000 schools, this is one of the largest country sample in PISA 2009. The first row reports the estimated coefficients of the six measures of PISA managerial practices: LDRSHP (overall leadership measure), RESPCURR (responsibility over curricula) and RESPRES (responsibility over expenditure) in columns from 1 to 3 , and the 3 sub-indices of Leadership, Operations and Monitoring in columns from 4 to 6 . Robust standard errors, clustered at principal/school level, are reported in parenthesis. We find that the measures of managerial practices are always statistically insignificant. ${ }^{52}$ The coefficients of the additional controls are very similar

\footnotetext{
${ }^{51}$ Among controls we include: a set of dummies for the number of school in competition (Q5), the number of students in the school (SCHSIZE), a dummy for private schools (SCHTYPE), the share of part-time teachers with respect to the total number of teachers, students' immigration status (IMMIG), their gender, their socio-economic background (ESCS), and an indicator for students repeating grades (Q7). We also control for area characteristics, including dummies for population density and alternatively regional-type of school. When we focus on the sample of 33 OECD countries we include countries fixed effects. Data for France are not available.

${ }^{52}$ We have replicated the same analysis with an alternative measure of management that excludes the last item of Q26, that refers to a managerial activity not explored by the WMS survey, and we obtain the same results.
} 
with that found in Table 4, suggesting that the difference is in variables that measure managerial practices rather than in other features of the survey.

We next extend the same analysis to all countries, exploiting the cross-country dimension of the PISA dataset by including the 33 available OECD countries in the regressions. Table 12 leads to very different conclusions from the ones based on the WMS: in the PISA sample the effect of managerial practices is always negative and, in two cases (LDRSHP and Operations), statistically significant. This is a puzzling result: although one might argue against the importance of SPs managerial practices for students' performance, it seems hard to justify a negative effect. One possibility is that less capable SPs are also more indulgent in self-assessing their performance. ${ }^{53}$

Overall, this analysis does not support the assertion that the WMS and the PISA surveys supply comparable indicators of management practices. Both the direct comparison and the regression analysis reveal marked differences between the two surveys. These disparities are likely to be due to both methodological differences in data collection and possible mis-measurement of the self-reported PISA managerial indices. They suggest that self assessment cannot substitute the direct assessment of SPs managerial capabilities by a third party.

\section{Conclusions}

This study investigates if the quality of managerial practices in schools affects students' achievements. To this aim, we measure managerial practices using the World Management Survey, an innovative methodology that enables us to construct robust measures of management quality comparable across countries and overcome standard mis-measurement problems that are typical of self-assessed measures of managerial ability that characterized previous studies in the field. Moreover, this methodology identifies the specific areas of managerial activity that matter most for successfully leading a school.

We first compare data on six industrialized countries (Canada, Italy, Germany, Sweden, the UK, the US) and find substantial heterogeneity in managerial practices across these countries. Countries that obtain the lowest scores on schools managerial quality (Italy and Germany) are also characterized by more centralized systems, with less autonomy at school level in many areas of management. Second, our analysis focuses on the Italian case for which we are able to match our indexes of managerial practices at the school level with the

\footnotetext{
${ }^{53}$ An alternative explanation is selection: better SPs are assigned to worse schools. To assess this possibility, one would need to consider the SPs appointment process in each country, something clearly beyond the scope of this paper.
} 
students' outcomes in the maths standardized test. In particular, in order to investigate the relationship between SPs managerial practices and students outcomes we estimate a standard education production function where students' test performance in mathematics is modeled as a function of SP managerial skills and of rich set of students, SPs and schools additional controls. We argue that our set of covariates allows us to control for the most likely sources of endogeneity, in particular, self selection of best principals into best schools.

The OLS estimates imply that increasing managerial practices by one unit, students' test results would increase by about 4.6\%. In other words, if Italian SPs implemented managerial practices of the same average quality as the the UK SPs (the best performer in terms of management), Italian students would close the gap in the math OECD PISA test with respect to the OECD average. In terms of specific areas of managerial practices, we find that the coefficients are positive in all categories, although statistically significant only for leadership and monitoring activities of school processes. The results survive a large series of checks, including the most likely endogeneity and selection concerns. All our exercises confirm that management quality is an important input of our estimated education production function.

Overall, the policy implications of these results are clear cut. A well-run schools contributes to improve students' cognitive achievements. Governments should therefore enact policies that take into account principals' selection and training in terms of managerial capabilities. 


\section{References}

Angrist, Joshua D, Erich Battistin, and Daniela Vuri. 2014. "In a Small Moment: Class Size and Moral Hazard in the Mezzogiorno." NBER Working Paper 20173.

Barbieri, Gianna, Claudio Rossetti, and Paolo Sestito. 2011. "The determinants of teacher mobility: Evidence using Italian teachers transfer applications." Economics of Education Review 30 (6):1430-1444.

Barro, Robert J and Jong-Wha Lee. 1994. "Sources of economic growth." In CarnegieRochester conference series on public policy, vol. 40. 1-46.

Bertrand, Marianne and Antoinette Schoar. 2003. "Managing with style: The effect of managers on firm policies." The Quarterly Journal of Economics 118 (4):1169-1208.

Bloom, Nicholas, Christos Genakos, Raffaella Sadun, and John Van Reenen. 2012. "Management practices across firms and countries." The Academy of Management Perspectives 26 (1):12-33.

Bloom, Nicholas, Renata Lemos, Raffaela Sadun, and John Van Reenen. 2014. "Does management matter in schools?" Paper presented at the Conference for 10 Years of the WMS, Harvard University.

Bloom, Nicholas and John Van Reenen. 2007. "Measuring and Explaining Management Practices Across Firms and Countries." The Quarterly Journal of Economics $122(4): 1351-1408$.

. 2010a. "New Approaches to Surveying Organizations." American Economic Review $100(2): 105-09$.

. 2010b. "Why do management practices differ across firms and countries?" The Journal of Economic Perspectives 24 (1):203-224.

- 2011. Human Resource Management and Productivity, Handbook of Labor Economics, vol. 4, chap. 19. Elsevier, 1697-1767.

Böhlmark, Anders, Erik Grönqvist, and Jonas Vlachos. 2012. "The headmaster ritual: the importance of management for school outcomes." IFAU Working Paper 201216.

Branch, Gregory F, Eric A Hanushek, and Steven G Rivkin. 2012. "Estimating the effect of leaders on public sector productivity: The case of school principals." NBER Working Paper 17803.

Bratti, Massimiliano, Daniele Checchi, and Antonio Filippin. 2007. "Geographical Differences in Italian Students' Mathematical Competencies: Evidence from PISA 2003." Giornale degli Economisti e Annali di Economia :299-333.

Brewer, Dominic J. 1993. "Principals and student outcomes: Evidence from U.S. high schools." Economics of Education Review 12 (4):281-292. 
Brunello, Giorgio and Daniele Checchi. 2007. "Does school tracking affect equality of opportunity? New international evidence." Economic Policy 22:781-861.

Brunello, Giorgio and Lorenzo Rocco. 2008. "Educational Standards in Private and Public Schools." The Economic Journal 118 (533):1866-1887.

Chetty, Raj, John N Friedman, and Jonah E Rockoff. 2011. "The long-term impacts of teachers: Teacher value-added and student outcomes in adulthood." NBER Working Paper 17699.

Cipollone, Piero, Pasqualino Montanaro, and Paolo Sestito. 2010. "Value-Added Measures in Italian High Schools: Problems and Findings." Giornale degli Economisti 69 (2):81114.

Coelli, Michael and David A Green. 2012. "Leadership effects: School principals and student outcomes." Economics of Education Review 31 (1):92-109.

Cullen, Julie Berry and Michael J. Mazzeo. 2008. "Implicit Performance Awards: An Empirical Analysis Of The Labor Market For Public School Administrators." mimeo.

Datar, Ashlesha and Bryce Mason. 2008. "Do reductions in class size crowd out parental investment in education?" Economics of Education Review 27 (6):712-723.

De Simone, Gianfranco. 2013. "Render unto Primary the Things which are Primary's. Inherited and Fresh Learning Divides in Italian Lower Secondary Education." Economics of Education Review 35 (C):12-23.

Dhuey, Elizabeth and Justin Smith. 2012. "How School Principals Influence Student Learning." Society for Research on Educational Effectiveness .

Di Liberto, Adriana, Fabiano Schivardi, and Giovanni Sulis. 2013. "Managerial practices and students performance." FGA Working Paper 49.

Eurydice. 2010. "Gender Differences in Educational Outcomes." Tech. rep., European Commission.

Faini, R., G. Galli, and F. Rossi. 1996. "Mobilità e disoccupazione in Italia: un'analisi dell'offerta di lavoro." In La mobilità della società italiana, edited by G. Galli.

Grissom, Jason and Susanna Loeb. 2011. "Triangulating Principal Effectiveness: How Perspectives of Parents, Teachers, and Assistant Principals Identify the Central Importance of Managerial Skills." Americal Educational Research Journal 48 (5):1091-1123.

Guiso, Luigi, Monte Ferdinando, Paola Sapienza, and Luigi Zingales. 2008. "Culture, Gender, and Math." Science 320:1164-1165.

Hallinger, Philip and Ronald H Heck. 1998. "Exploring the Principal's Contribution to School Effectiveness: 1980-1995." School effectiveness and school improvement 9 (2):157191. 
Hanushek, Eric A., Susanne Link, and Ludger Woessmann. 2011. "Does School Autonomy Make Sense Everywhere? Panel Estimates from PISA." NBER Working Paper 17591.

Hanushek, Eric A and Steven G Rivkin. 2006. "Teacher quality." Handbook of the Economics of Education 2:1051-1078.

Hanushek, Eric A. and Ludger Woessmann. 2011. "How much do educational outcomes matter in OECD countries?" Economic Policy 26 (67):427-491.

INVALSI. 2011. "Rapporto tecnico sulle caratteristiche delle prove INVALSI 2011." Tech. rep., INVALSI.

Lavy, Victor. 2008. "Does Raising the Principal's Wage Improve the School's Outcomes? Quasi-experimental Evidence from an Unusual Policy Experiment in Israel." The Scandinavian Journal of Economics 110 (4):639-662.

Lazear, Edward P. 2001. "Educational Production." Quarterly Journal of Economics $116(3): 777-803$.

Li, Danielle. 2012. "School Accountability and Principal Mobility: How No Child Left Behind Affects the Allocation of School Leaders." mimeo, MIT.

Loeb, Susanna, Demetra Kalogrides, and Tara Béteille. 2012. "Effective schools: Teacher hiring, assignment, development, and retention." Education Finance and Policy 7 (3):269-304.

Lucas, Robert E. Jr. 1988. "On the mechanics of economic development." Journal of monetary economics 22 (1):3-42.

Lucifora, Claudio and Marco Tonello. 2012. "Students' Cheating as a Social Interaction: Evidence from a Randomized Experiment in a National Evaluation Program." IZA Working Paper 6967.

OECD. 2012. Public and Private Schools: How Management and Funding Relate to their Socio-economic Profile. Paris, OECD Publishing.

Pont, Beatriz, Deborah Nusche, Hunter Moorman, and Hopkins David. 2008. Improving school leadership, Volume 1: Policy and practice. Paris, OECD Publishing.

Rivkin, Steven G, Eric A Hanushek, and John F Kain. 2005. "Teachers, schools, and academic achievement." Econometrica 73 (2):417-458.

Robinson, Viviane M. J., Claire A. Lloyd, and Kenneth J. Rowe. 2008. "The Impact of Leadership on Student Outcomes: An Analysis of the Differential Effects of Leadership Types." Educational Administration Quarterly 44:635674.

Rockoff, Jonah E. 2004. "The impact of individual teachers on student achievement: Evidence from panel data." The American Economic Review 94 (2):247-252. 


\section{Figures and Tables}

Figure 1: Average Managerial Practices across Countries

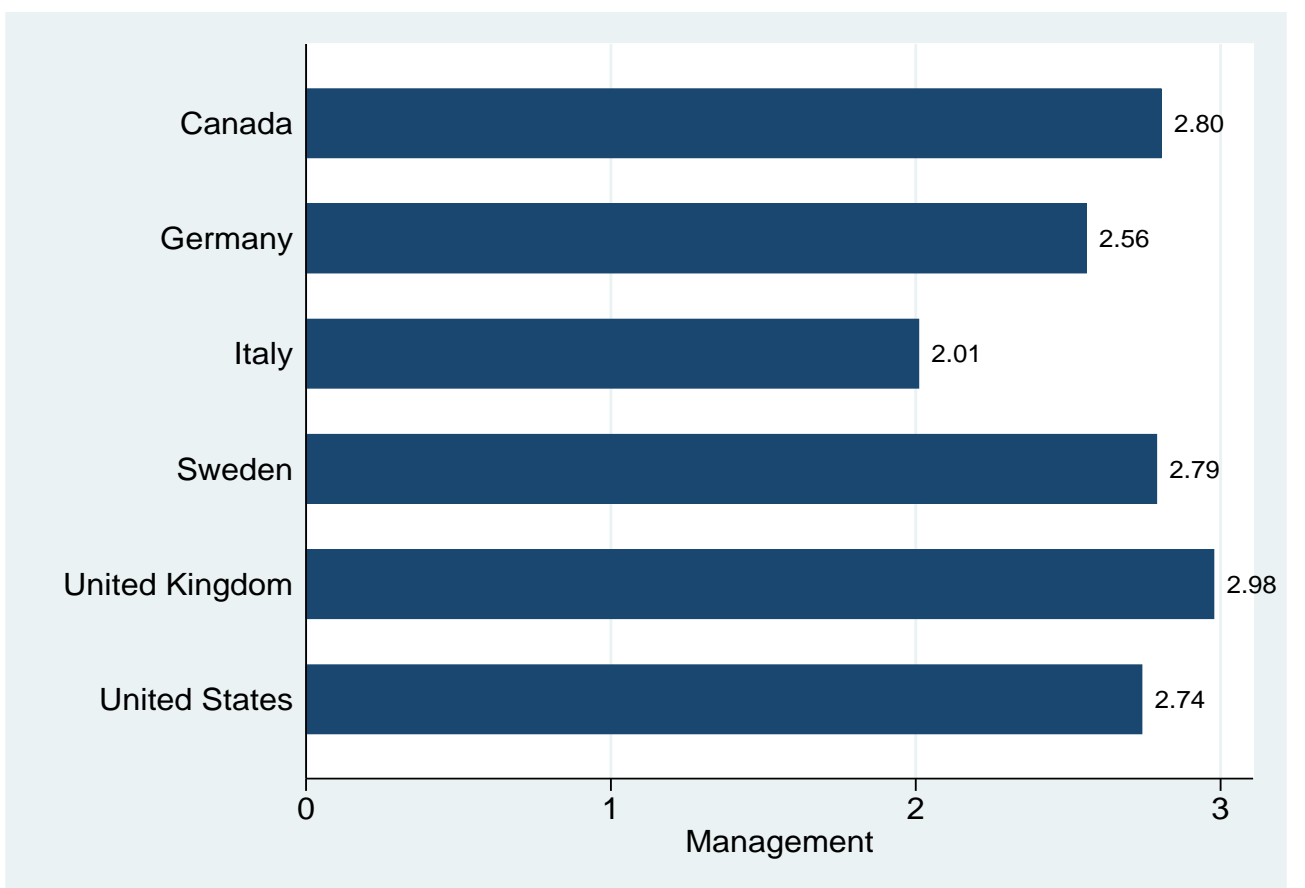

Notes: For WMS cross country data, excluding Italy, see (Bloom et al., 2012). 
Figure 2: Distribution of Managerial Practices within Countries

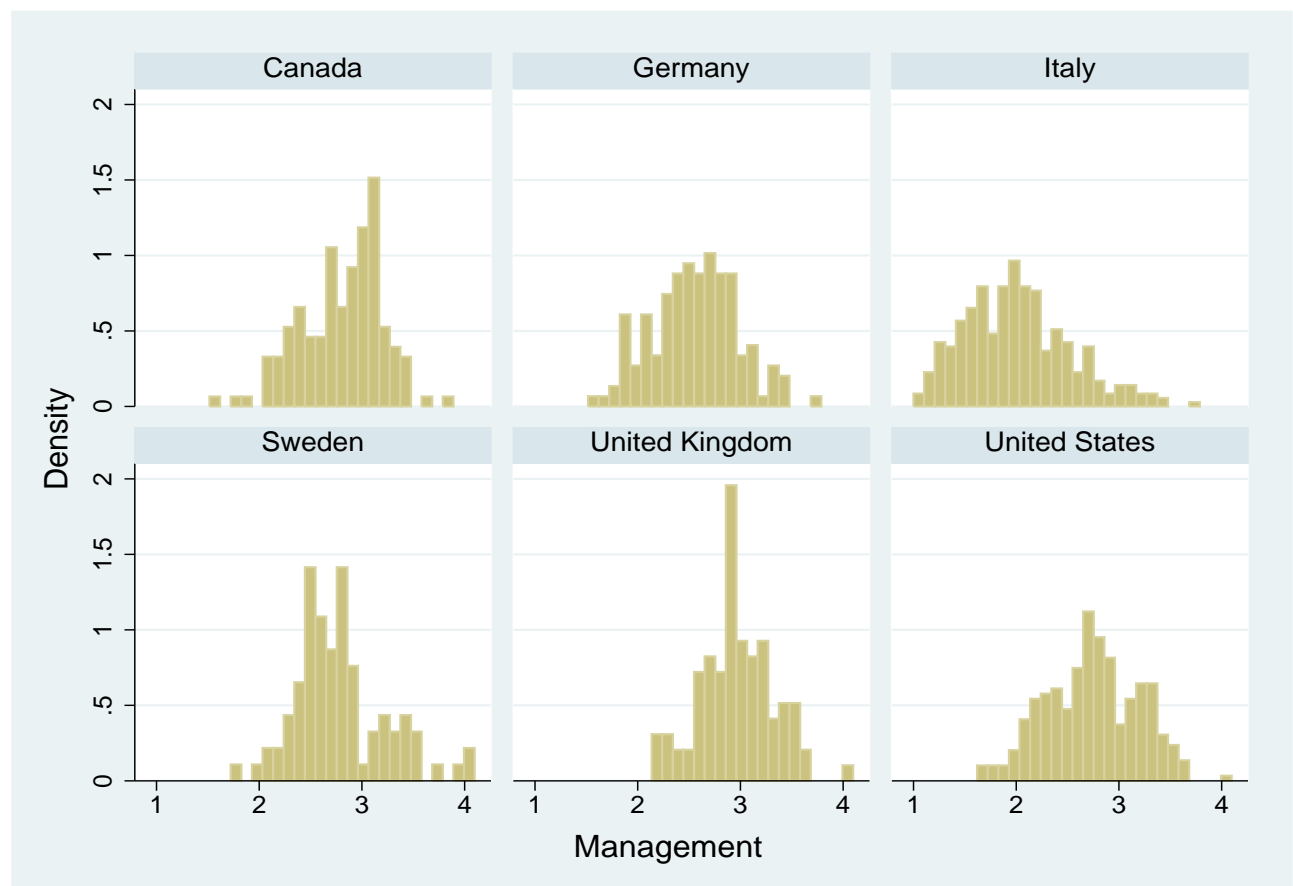

Notes: For WMS cross country data, excluding Italy, see (Bloom et al., 2012). 
Figure 3: PISA and WMS School Management Indices Rescaled

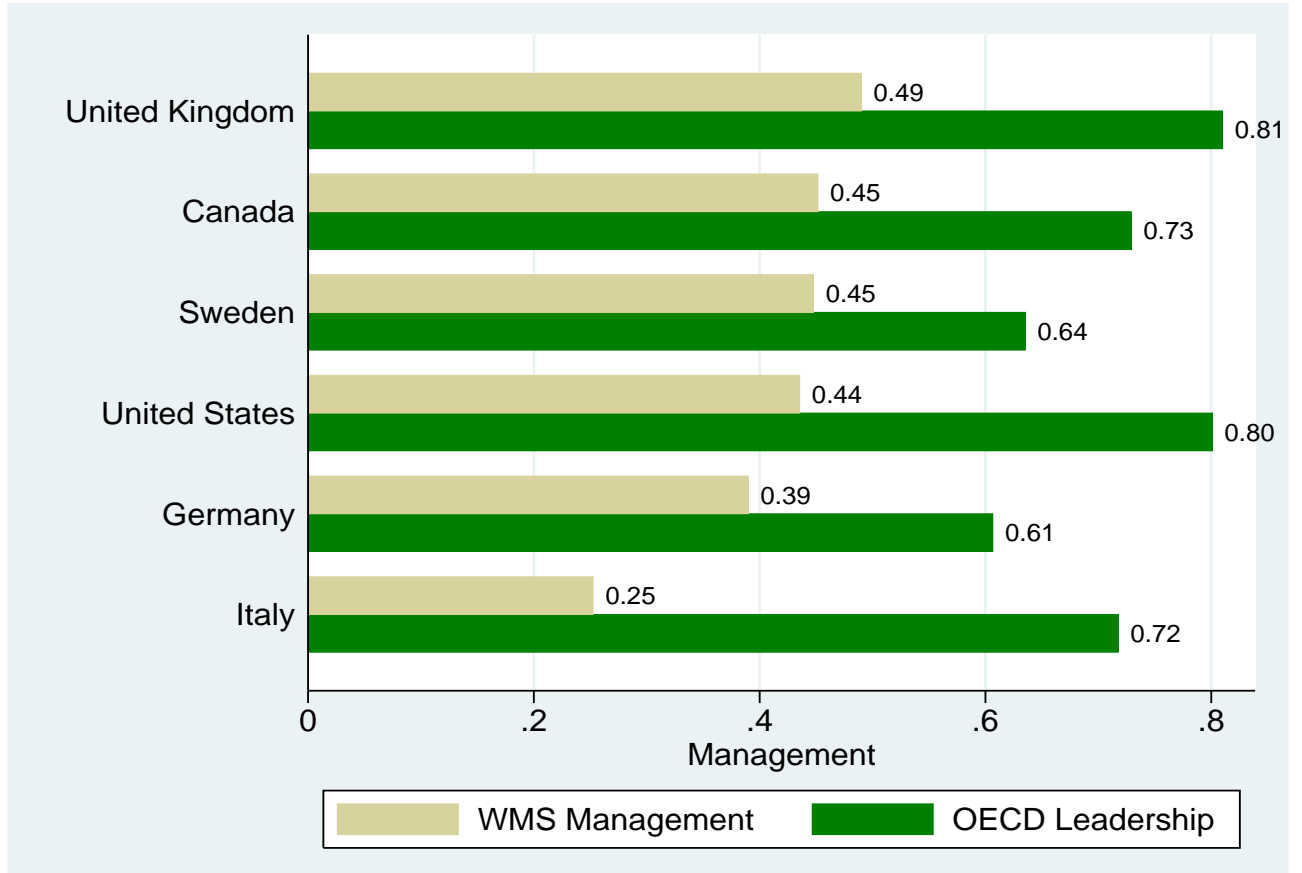

Figure 4: Distribution of PISA and WMS School Management Indices Rescaled

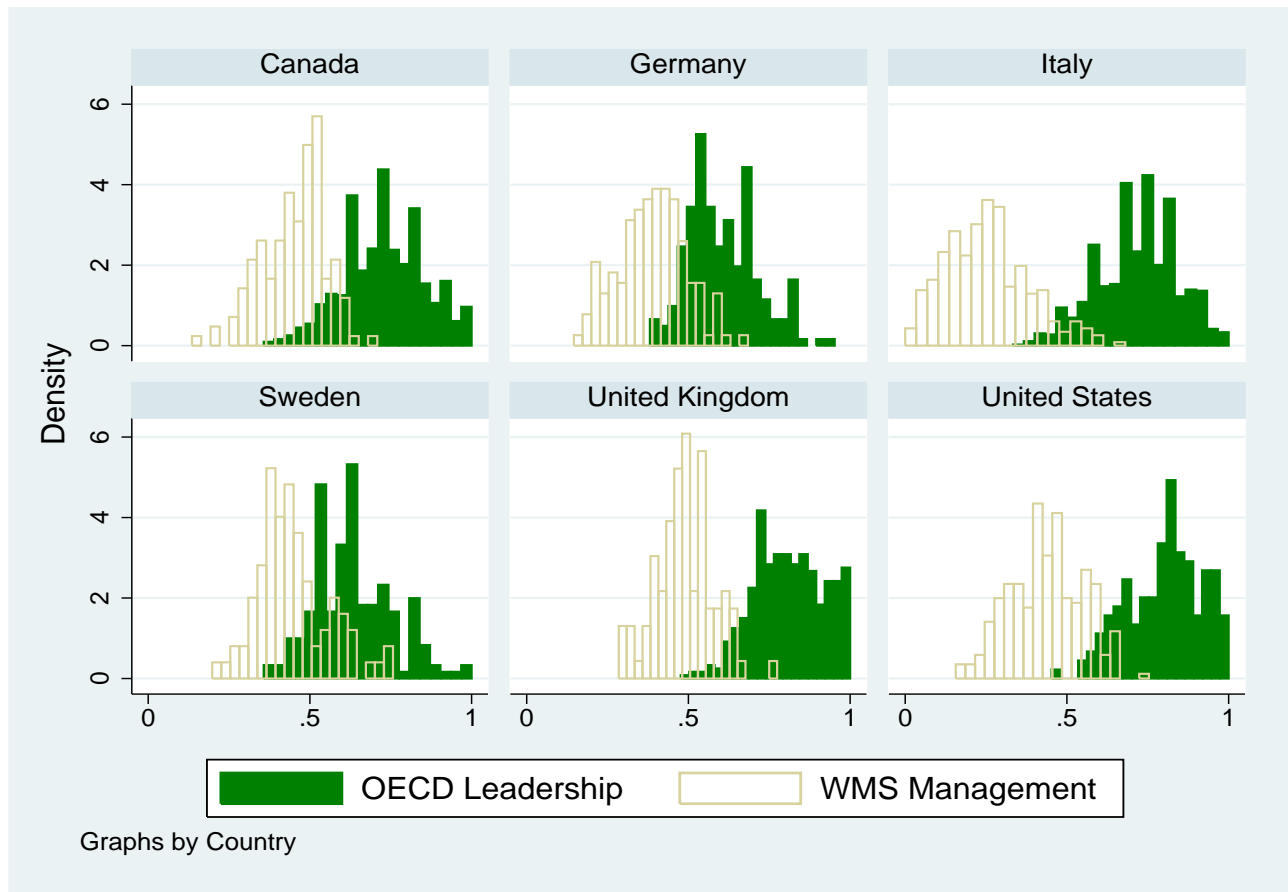


Figure 5: Distribution of PISA and the Alternative WMS School Management Indices Rescaled

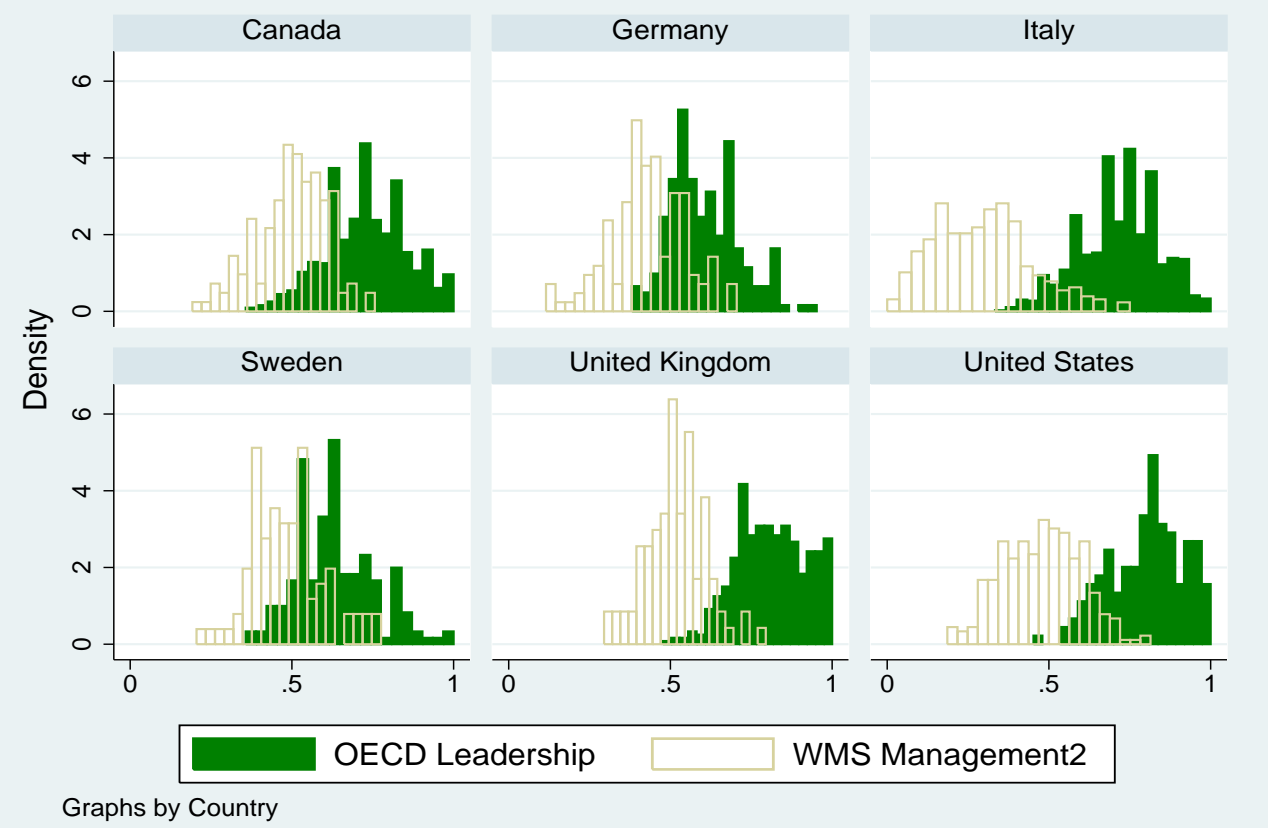


Table 1: Descriptive Statistics: Cross Country Comparison

\begin{tabular}{lcccccc}
\hline \hline & Canada & Germany & Italy & Sweden & United Kingdom & United States \\
& & & & & & \\
percentiles & & & & & & \\
10th & 2.26 & 1.97 & 1.37 & 2.32 & 2.53 & 2.15 \\
50th & 2.87 & 2.55 & 1.99 & 2.74 & 2.95 & 2.75 \\
90 th & 3.26 & 3.10 & 2.71 & 3.40 & 3.44 & 3.32 \\
& & & & & & \\
mean & 2.81 & 2.56 & 2.01 & 2.80 & 2.96 & 2.74 \\
st. dev. & 0.39 & 0.41 & 0.51 & 0.44 & 0.36 & \\
& & & & & & \\
percentile ratios & 1.44 & 1.57 & 1.98 & 1.47 & 1.36 & 1.54 \\
$90 / 10$ & 1.27 & 1.29 & 1.45 & 1.18 & 1.17 & 1.28 \\
$50 / 10$ & 1.14 & 1.22 & 1.36 & 1.24 & 1.17 & \\
$90 / 50$ & & & & & & \\
& 147 & 143 & 341 & 89 & 94 & 285 \\
observations & & & & & \\
\hline \hline
\end{tabular}

Notes: For cross country data, excluding Italy, see Bloom et al. $(2012,2014)$. The overall measure of Management includes all sections, i.e., Leadership, Operations, Monitoring, Targets and People. 
Table 2: Descriptive statistics: overall sample

\begin{tabular}{|c|c|c|c|c|c|}
\hline Variable & Mean & Std. Dev. & Min. & Max. & Obs. \\
\hline \multicolumn{6}{|c|}{ Panel A: School/Principal Characteristics } \\
\hline management & 2.00 & 0.51 & 1 & 3.74 & 341 \\
\hline people & 1.84 & 0.49 & 1 & 3.67 & 341 \\
\hline targets & 1.77 & 0.54 & 1 & 3.6 & 341 \\
\hline operations & 2.23 & 0.68 & 1 & 4.5 & 341 \\
\hline leader & 2.17 & 0.59 & 1 & 4 & 341 \\
\hline monitoring & 2.14 & 0.68 & 1 & 4.60 & 341 \\
\hline principal's age & 58.64 & 7.02 & 32 & 80 & 338 \\
\hline gender of principal, female $=1$ & 0.36 & 0.48 & 0 & 1 & 325 \\
\hline tenure in school & 6.51 & 5.98 & 1 & 40 & 324 \\
\hline competition & 2.51 & 2.68 & 0 & 15 & 339 \\
\hline school size & 6.19 & 0.82 & 3.93 & 7.5 & 325 \\
\hline dummy private school & 0.22 & 0.41 & 0 & 1 & 325 \\
\hline teacher turnover & 4.62 & 6.22 & 0 & 50 & 318 \\
\hline dummy $=1$ post-2006 reform & 0.32 & 0.47 & 0 & 1 & 325 \\
\hline \multicolumn{6}{|l|}{ Panel B: Students Characteristics } \\
\hline test score math normalized & 48.59 & 17.96 & 0 & 100 & 33727 \\
\hline Lyceum & 0.48 & 0.5 & 0 & 1 & 34244 \\
\hline Vocational & 0.21 & 0.41 & 0 & 1 & 34244 \\
\hline Technical & 0.31 & 0.46 & 0 & 1 & 34244 \\
\hline dummy "Istituto Superiore" & 0.35 & 0.48 & 0 & 1 & 37777 \\
\hline immigrant 1st generation & 0.06 & 0.23 & 0 & 1 & 37362 \\
\hline immigrant 2nd generation & 0.02 & 0.16 & 0 & 1 & 37362 \\
\hline gender of student, female $=1$ & 0.5 & 0.5 & 0 & 1 & 37360 \\
\hline escs, socio-economic background & 0.04 & 0.99 & -3.66 & 2.07 & 33254 \\
\hline student behind & 0.22 & 0.42 & 0 & 1 & 37349 \\
\hline dummy rural area & 0.11 & 0.31 & 0 & 1 & 37777 \\
\hline dummy non rural area & 0.36 & 0.48 & 0 & 1 & 37777 \\
\hline dummy urban area & 0.54 & 0.5 & 0 & 1 & 37777 \\
\hline ln of bank deposits per capita & 4.29 & 1.18 & 0 & 5.38 & 37777 \\
\hline
\end{tabular}

Notes: In panel A data are aggregated at the principal level, in Panel B at students' level. principal's age and tenure are measured in years, competition is the number of schools with similar curricula within 30 minutes drive from school, dummy post-2006 reform is equal to 1 for principals with 4 years (or less) of experience, school size is the natural logarithm of the number of students in school, teacher turnover is the share of teachers that left the school in previous year, immigrant 1st generation are students born abroad of foreign-born parents, immigrant 2nd generation are native-born students of foreign-born parents, student behind is a dummy for students older than regular ones. 
Table 3: Descriptive statistics: sub-sample of principals leading a school they have chosen

\begin{tabular}{lccccc}
\hline \multicolumn{1}{c}{ Variable } & Mean & Std. Dev. & Min. & Max. & Obs. \\
\hline Panel A: School/Principal Characteristics & & & & & \\
management & 2.01 & 0.5 & 1 & 3.74 & 260 \\
people & 1.82 & 0.47 & 1 & 3.5 & 260 \\
targets & 1.78 & 0.54 & 1 & 3.6 & 260 \\
operations & 2.25 & 0.68 & 1 & 4.5 & 260 \\
leader & 2.19 & 0.58 & 1 & 4 & 260 \\
monitoring & 2.16 & 0.68 & 1 & 4.60 & 260 \\
principal's age & 58.18 & 6.73 & 32 & 80 & 257 \\
gender of principal, female=1 & 0.37 & 0.48 & 0 & 1 & 260 \\
tenure in school & 6.55 & 5.86 & 1 & 40 & 259 \\
competition & 2.34 & 2.34 & 0 & 11 & 259 \\
school size & 6.27 & 0.8 & 3.93 & 7.5 & 260 \\
dummy private school & 0.17 & 0.37 & 0 & 1 & 260 \\
teacher turnover & 4.78 & 6.13 & 0 & 50 & 257 \\
dummy=1 post-2006 reform & 0.32 & 0.47 & 0 & 1 & 260 \\
& & & & & \\
Panel B: Students Characteristics & & & & & \\
test score math normalized & 49.04 & 17.95 & 0 & 100 & 29198 \\
Lyceum & 0.48 & 0.5 & 0 & 1 & 29649 \\
Vocational & 0.2 & 0.4 & 0 & 1 & 29649 \\
Technical & 0.32 & 0.47 & 0 & 1 & 29649 \\
dummy "istituto superiore" & 0.37 & 0.48 & 0 & 1 & 32728 \\
immigrant 1st generation & 0.06 & 0.24 & 0 & 1 & 32366 \\
immigrant 2nd generation & 0.02 & 0.15 & 0 & 1 & 32366 \\
gender of student, female=1 & 0.5 & 0.5 & 0 & 1 & 32361 \\
escs, socio-economic background & 0.03 & 0.98 & -3.66 & 2.07 & 28828 \\
student behind & 0.22 & 0.41 & 0 & 1 & 32358 \\
dummy rural area & 0.12 & 0.32 & 0 & 1 & 32728 \\
dummy non rural area & 0.35 & 0.48 & 0 & 1 & 32728 \\
dummy urban area & 0.54 & 0.5 & 0 & 1 & 32728 \\
ln of bank deposits per capita & 4.27 & 1.2 & 0 & 5.38 & 32728 \\
\hline \hline
\end{tabular}

Notes: This sub-sample includes only principals that have been assigned to a school they requested, excluding those that manage a school assigned by the Regional School Authorities. In panel A data are aggregated at the principal level, in Panel B at students' level. See Notes to Table 2 for additional details regarding the variables. 
Table 4: Baseline model

\begin{tabular}{|c|c|c|c|c|c|c|}
\hline $\begin{array}{l}\text { Dependent Variable } \\
\text { Test results (Math) }\end{array}$ & $\begin{array}{c}(1) \\
\text { Management }\end{array}$ & $\begin{array}{c}(2) \\
\text { Leadership }\end{array}$ & $\begin{array}{c}(3) \\
\text { Operations }\end{array}$ & $\begin{array}{c}(4) \\
\text { Monitoring }\end{array}$ & $\begin{array}{c}(5) \\
\text { Targets }\end{array}$ & $\begin{array}{c}(6) \\
\text { People }\end{array}$ \\
\hline managerial practices & $\begin{array}{l}2.24^{*} \\
(1.31)\end{array}$ & $\begin{array}{l}2.72^{* *} \\
(1.13)\end{array}$ & $\begin{array}{l}1.20 \\
(0.86)\end{array}$ & $\begin{array}{c}2.36^{* *} \\
(0.96)\end{array}$ & $\begin{array}{c}0.98 \\
(1.24)\end{array}$ & $\begin{array}{c}0.73 \\
(1.44)\end{array}$ \\
\hline age principal & $\begin{array}{c}0.17 \\
(0.12)\end{array}$ & $\begin{array}{c}0.17 \\
(0.12)\end{array}$ & $\begin{array}{c}0.16 \\
(0.12)\end{array}$ & $\begin{array}{l}0.19^{*} \\
(0.11)\end{array}$ & $\begin{array}{c}0.14 \\
(0.12)\end{array}$ & $\begin{array}{c}0.13 \\
(0.12)\end{array}$ \\
\hline gender principal $($ female $=1$ ) & $\begin{array}{c}0.44 \\
(1.31)\end{array}$ & $\begin{array}{c}0.28 \\
(1.27)\end{array}$ & $\begin{array}{c}0.53 \\
(1.31)\end{array}$ & $\begin{array}{c}0.63 \\
(1.25)\end{array}$ & $\begin{array}{c}0.60 \\
(1.35)\end{array}$ & $\begin{array}{c}0.69 \\
(1.32)\end{array}$ \\
\hline tenure in school & $\begin{array}{l}-0.03 \\
(0.11)\end{array}$ & $\begin{array}{l}-0.03 \\
(0.11)\end{array}$ & $\begin{array}{l}-0.01 \\
(0.11)\end{array}$ & $\begin{array}{l}-0.03 \\
(0.11)\end{array}$ & $\begin{array}{l}-0.02 \\
(0.11)\end{array}$ & $\begin{array}{l}-0.02 \\
(0.11)\end{array}$ \\
\hline competition & $\begin{array}{c}0.25 \\
(0.27)\end{array}$ & $\begin{array}{c}0.29 \\
(0.27)\end{array}$ & $\begin{array}{c}0.22 \\
(0.28)\end{array}$ & $\begin{array}{c}0.27 \\
(0.27)\end{array}$ & $\begin{array}{c}0.22 \\
(0.28)\end{array}$ & $\begin{array}{c}0.21 \\
(0.28)\end{array}$ \\
\hline school size & $\begin{array}{l}-0.99 \\
(1.01)\end{array}$ & $\begin{array}{l}-1.18 \\
(1.00)\end{array}$ & $\begin{array}{l}-0.83 \\
(1.03)\end{array}$ & $\begin{array}{l}-0.92 \\
(1.01)\end{array}$ & $\begin{array}{l}-0.87 \\
(1.03)\end{array}$ & $\begin{array}{l}-0.80 \\
(1.01)\end{array}$ \\
\hline private school & $\begin{array}{c}-5.67^{* *} \\
(2.22)\end{array}$ & $\begin{array}{c}-5.69^{* * *} \\
(2.18)\end{array}$ & $\begin{array}{c}-5.35^{* *} \\
(2.23)\end{array}$ & $\begin{array}{c}-5.00^{* *} \\
(2.20)\end{array}$ & $\begin{array}{c}-5.49 * * \\
(2.23)\end{array}$ & $\begin{array}{c}-6.00^{* *} \\
(2.40)\end{array}$ \\
\hline teacher turnover & $\begin{array}{c}0.11 \\
(0.08)\end{array}$ & $\begin{array}{c}0.12 \\
(0.08)\end{array}$ & $\begin{array}{c}0.11 \\
(0.08)\end{array}$ & $\begin{array}{c}0.11 \\
(0.08)\end{array}$ & $\begin{array}{c}0.11 \\
(0.08)\end{array}$ & $\begin{array}{c}0.11 \\
(0.08)\end{array}$ \\
\hline lyceum school & $\begin{array}{c}5.20^{* * *} \\
(1.33)\end{array}$ & $\begin{array}{c}5.22^{* * *} \\
(1.32)\end{array}$ & $\begin{array}{c}5.09 * * * \\
(1.35)\end{array}$ & $\begin{array}{c}5.19^{* * *} \\
(1.28)\end{array}$ & $\begin{array}{c}5.11^{* * *} \\
(1.35)\end{array}$ & $\begin{array}{c}5.18^{* * *} \\
(1.36)\end{array}$ \\
\hline vocational school & $\begin{array}{c}-9.25^{* * *} \\
(1.32)\end{array}$ & $\begin{array}{c}-9.27^{* * *} \\
(1.33)\end{array}$ & $\begin{array}{c}-9.27^{* * *} \\
(1.35)\end{array}$ & $\begin{array}{c}-9.23^{* * *} \\
(1.30)\end{array}$ & $\begin{array}{c}-9.41^{* * *} \\
(1.35)\end{array}$ & $\begin{array}{c}-9.40 * * * \\
(1.34)\end{array}$ \\
\hline "istituto superiore" & $\begin{array}{c}-2.85^{* *} \\
(1.21)\end{array}$ & $\begin{array}{c}-2.93^{* *} \\
(1.20)\end{array}$ & $\begin{array}{c}-2.72^{* *} \\
(1.19)\end{array}$ & $\begin{array}{c}-2.79 * * \\
(1.17)\end{array}$ & $\begin{array}{c}-2.76^{* *} \\
(1.25)\end{array}$ & $\begin{array}{c}-2.62^{* *} \\
(1.21)\end{array}$ \\
\hline immigrant 1st generation & $\begin{array}{c}-1.98^{* * *} \\
(0.60)\end{array}$ & $\begin{array}{c}-1.87^{* * *} * \\
(0.60)\end{array}$ & $\begin{array}{c}-1.94^{* * *} \\
(0.60)\end{array}$ & $\begin{array}{c}-2.08^{* * *} * \\
(0.60)\end{array}$ & $\begin{array}{c}-1.99 * * * \\
(0.60)\end{array}$ & $\begin{array}{c}-1.96^{* * *} \\
(0.60)\end{array}$ \\
\hline immigrant 2nd generation & $\begin{array}{c}-2.26^{* * *} \\
(0.63)\end{array}$ & $\begin{array}{c}-2.21^{* * *} \\
(0.63)\end{array}$ & $\begin{array}{c}-2.23^{* * *} \\
(0.63)\end{array}$ & $\begin{array}{c}-2.30^{* * *} \\
(0.62)\end{array}$ & $\begin{array}{c}-2.31^{* * *} \\
(0.63)\end{array}$ & $\begin{array}{c}-2.29 * * * \\
(0.63)\end{array}$ \\
\hline gender_student $($ female $=1$ ) & $\begin{array}{c}-6.60^{* * *} \\
(0.53)\end{array}$ & $\begin{array}{c}-6.59^{* * *} \\
(0.53)\end{array}$ & $\begin{array}{c}-6.62^{* * *} \\
(0.54)\end{array}$ & $\begin{array}{c}-6.59^{* * *} \\
(0.52)\end{array}$ & $\begin{array}{c}-6.66^{* * *} \\
(0.54)\end{array}$ & $\begin{array}{c}-6.66^{* * *} \\
(0.54)\end{array}$ \\
\hline socio_economic background & $\begin{array}{c}1.07^{* * *} \\
(0.18)\end{array}$ & $\begin{array}{c}1.06^{* * *} \\
(0.18)\end{array}$ & $\begin{array}{c}1.08^{* * *} \\
(0.18)\end{array}$ & $\begin{array}{c}1.09^{* * *} \\
(0.18)\end{array}$ & $\begin{array}{c}1.07 * * * \\
(0.18)\end{array}$ & $\begin{array}{c}1.06^{* * *} \\
(0.18)\end{array}$ \\
\hline student behind & $\begin{array}{c}-5.22^{* * *} \\
(0.40)\end{array}$ & $\begin{array}{c}-5.18^{* * *} \\
(0.40)\end{array}$ & $\begin{array}{c}-5.25^{* * *} \\
(0.41)\end{array}$ & $\begin{array}{c}-5.22^{* * *} \\
(0.40)\end{array}$ & $\begin{array}{c}-5.27^{* * *} \\
(0.40)\end{array}$ & $\begin{array}{c}-5.28^{* * *} \\
(0.40)\end{array}$ \\
\hline dummy rural areas & $\begin{array}{l}-0.26 \\
(2.04)\end{array}$ & $\begin{array}{l}-0.50 \\
(1.97)\end{array}$ & $\begin{array}{l}-0.29 \\
(2.03)\end{array}$ & $\begin{array}{c}0.10 \\
(2.05)\end{array}$ & $\begin{array}{l}-0.42 \\
(2.04)\end{array}$ & $\begin{array}{l}-0.45 \\
(1.99)\end{array}$ \\
\hline dummy non rural areas & $\begin{array}{c}0.03 \\
(1.20)\end{array}$ & $\begin{array}{l}-0.15 \\
(1.17)\end{array}$ & $\begin{array}{l}-0.10 \\
(1.18)\end{array}$ & $\begin{array}{c}0.33 \\
(1.24)\end{array}$ & $\begin{array}{l}-0.10 \\
(1.18)\end{array}$ & $\begin{array}{l}-0.19 \\
(1.16)\end{array}$ \\
\hline ln deposits per capita & $\begin{array}{c}0.80^{* *} \\
(0.38)\end{array}$ & $\begin{array}{c}0.83^{* *} \\
(0.38)\end{array}$ & $\begin{array}{c}0.77^{* *} \\
(0.39)\end{array}$ & $\begin{array}{c}0.81^{* *} \\
(0.39)\end{array}$ & $\begin{array}{c}0.79^{* *} \\
(0.38)\end{array}$ & $\begin{array}{c}0.77^{* *} \\
(0.38)\end{array}$ \\
\hline Constant & $\begin{array}{c}42.25^{* * *} \\
(11.73)\end{array}$ & $\begin{array}{c}42.58^{* * *} \\
(11.32)\end{array}$ & $\begin{array}{c}42.96^{* * *} \\
(12.08)\end{array}$ & $\begin{array}{c}39.65^{* * *} \\
(11.35)\end{array}$ & $\begin{array}{c}45.72^{* * *} \\
(11.55)\end{array}$ & $\begin{array}{c}46.96^{* * *} \\
(11.41)\end{array}$ \\
\hline Observations & 27775 & 27775 & 27775 & 27775 & 27775 & 27775 \\
\hline R-squared & 0.250 & 0.252 & 0.248 & 0.253 & 0.247 & 0.247 \\
\hline
\end{tabular}

Notes: Standard errors clustered at school level in parentheses: ${ }^{* * *} p<0.01,{ }^{* *} p<0.05,{ }^{*} p<0.1$. Dependent variable is standardized test score in mathematics. All regressions include regional dummies. Age of principal and tenure in school are measured in years. Competition is the number of schools with similar curricula within 30 minutes drive. School size is the natural logarithm of the number of students in school. Private is a dummy equal to one for private schools. istituto superiore is a dummy for schools offering different curricula (See also Section 7.2). Lyceum and vocational are dummies equal to 1 for each school type (technical school is the omitted dummy). Teacher turnover is the share of teacher turnover in the previous school year. Immigrant 1st generation are students born abroad of foreign-born parents, immigrant 2nd generation are native-born children of foreign-born parents. Student behind is a dummy equal to 1 if the student is older than regular. L 4 of deposits is the natural logarithm of bank deposits per capita at the municipal level. Dummies for urbanization are equal to 1 for rural areas and non rural areas (urban area is the omitted category). 
Table 5: IV model

\begin{tabular}{|c|c|c|c|c|c|c|}
\hline $\begin{array}{l}\text { Dependent Variable } \\
\text { Test results (Math) }\end{array}$ & $\begin{array}{c}(1) \\
\text { Management } \\
\end{array}$ & $\begin{array}{c}(2) \\
\text { Leadership } \\
\end{array}$ & $\begin{array}{c}(3) \\
\text { Operations } \\
\end{array}$ & $\begin{array}{c}(4) \\
\text { Monitoring } \\
\end{array}$ & $\begin{array}{c}(5) \\
\text { Targets }\end{array}$ & $\begin{array}{c}(6) \\
\text { People } \\
\end{array}$ \\
\hline managerial practices & $\begin{array}{l}19.32^{*} \\
(11.11)\end{array}$ & $\begin{array}{c}29.52 \\
(23.65)\end{array}$ & $\begin{array}{c}30.73 \\
(35.63)\end{array}$ & $\begin{array}{c}11.82^{* *} \\
(5.96)\end{array}$ & $\begin{array}{l}16.71^{*} \\
(9.35)\end{array}$ & $\begin{array}{c}25.37 \\
(16.71)\end{array}$ \\
\hline principal characteristics & Yes & Yes & Yes & Yes & Yes & Yes \\
\hline school characteristics & Yes & Yes & Yes & Yes & Yes & Yes \\
\hline student characteristics & Yes & Yes & Yes & Yes & Yes & Yes \\
\hline area characteristics & Yes & Yes & Yes & Yes & Yes & Yes \\
\hline regional dummies & Yes & Yes & Yes & Yes & Yes & Yes \\
\hline Observations & 27775 & 27775 & 27775 & 27775 & 27775 & 27775 \\
\hline First-stage F statistic & 4.29 & 1.59 & 0.77 & 6.09 & 5.44 & 3.28 \\
\hline $\operatorname{AR}(95 \%)$ & {$[3.93,62.85]$} & $\begin{array}{l}{[-63.20,-35.10] \mathrm{U}} \\
{[6.11,122.24]}\end{array}$ & $\begin{array}{c}{[-108.91,-18.64] \mathrm{U}} \\
{[6.75,170.38]}\end{array}$ & {$[2.62,35.17]$} & {$[3.01,53.38]$} & {$[4.86,90.85]$} \\
\hline No. clusters & 249 & 249 & 249 & 249 & 249 & 249 \\
\hline
\end{tabular}

Notes: Standard errors clustered at school level in parentheses: ${ }^{* * *} p<0.01,{ }^{* *} p<0.05,{ }^{*} p<0.1$. The instrumental variable for managerial practices is a dummy $=1$ if the principal has experience in post less or equal to 4 years (or dummy post-2006 reform). AR (95\%) reports the Anderson-Rubin 95\% confidence intervals (on managerial practices) robust to weak instruments. More on this in Section 8. For all these specifications, the set of additional controls is identical to those included in Table 4, results not reported but available upon request. See also Notes to Table 4 for additional details regarding control variables. 
Table 6: Sorting, heterogeneity and cheating

\begin{tabular}{|c|c|c|c|c|c|c|}
\hline $\begin{array}{l}\text { Dependent Variable } \\
\text { Test results (Math) }\end{array}$ & $\begin{array}{c}(1) \\
\text { Management }\end{array}$ & $\begin{array}{c}(2) \\
\text { Leadership }\end{array}$ & $\begin{array}{c}(3) \\
\text { Operations }\end{array}$ & $\begin{array}{c}(4) \\
\text { Monitoring }\end{array}$ & $\begin{array}{c}(5) \\
\text { Targets }\end{array}$ & $\begin{array}{c}(6) \\
\text { People }\end{array}$ \\
\hline \multicolumn{7}{|l|}{$\begin{array}{l}\text { Panel A: Students' sorting } \\
\text { Isolated schools }\end{array}$} \\
\hline managerial practices & $4.97^{*}$ & $7.37^{* * *}$ & 1.73 & $3.29 *$ & 3.07 & $4.75^{*}$ \\
\hline Observations & $\begin{array}{c}(2.623) \\
5,954\end{array}$ & $\begin{array}{c}(2.235) \\
5,954\end{array}$ & $\begin{array}{c}(2.128) \\
5,954\end{array}$ & $\begin{array}{c}(1.708) \\
5,954\end{array}$ & $\begin{array}{c}(2.400) \\
5,954\end{array}$ & $\begin{array}{c}(2.501) \\
5,954\end{array}$ \\
\hline \multicolumn{7}{|l|}{ Other schools in competition } \\
\hline managerial practices & $2.67^{*}$ & $2.69^{* *}$ & 1.40 & $2.72^{* *}$ & 1.49 & 1.17 \\
\hline Observations & $\begin{array}{l}(1.416) \\
21,821\end{array}$ & $\begin{array}{l}(1.175) \\
21,821\end{array}$ & $\begin{array}{l}(0.954) \\
21,821\end{array}$ & $\begin{array}{l}(1.093) \\
21,821\end{array}$ & $\begin{array}{l}(1.343) \\
21,821\end{array}$ & $\begin{array}{l}(1.604) \\
21,821\end{array}$ \\
\hline \multicolumn{7}{|c|}{$\begin{array}{l}\text { Panel B: Effect heterogeneity } \\
\text { Low socio-economic background }\end{array}$} \\
\hline managerial practices & $4.17^{* *}$ & $3.62^{* *}$ & $1.98^{*}$ & $4.04^{* * *}$ & 1.67 & 3.70 \\
\hline Observations & $\begin{array}{l}(1.938) \\
14,099\end{array}$ & $\begin{array}{l}(1.704) \\
14,099\end{array}$ & $\begin{array}{l}(1.133) \\
14,099\end{array}$ & $\begin{array}{l}(1.314) \\
14,099\end{array}$ & $\begin{array}{l}(1.920) \\
14,099\end{array}$ & $\begin{array}{l}(2.374) \\
14,099\end{array}$ \\
\hline \multicolumn{7}{|c|}{ High socio-economic background } \\
\hline managerial practices & 1.52 & $2.31^{*}$ & 0.68 & 1.71 & 1.14 & -0.72 \\
\hline Observations & $\begin{array}{l}(1.649) \\
13,676\end{array}$ & $\begin{array}{l}(1.261) \\
13,676\end{array}$ & $\begin{array}{l}(1.278) \\
13,676\end{array}$ & $\begin{array}{l}(1.093) \\
13,676\end{array}$ & $\begin{array}{l}(1.608) \\
13,676\end{array}$ & $\begin{array}{l}(1.917) \\
13,676\end{array}$ \\
\hline \multicolumn{7}{|l|}{ Panel C: Cheating } \\
\hline & $(1.356)$ & $(1.167)$ & $(0.890)$ & $(0.999)$ & $(1.272)$ & $(1.480)$ \\
\hline managerial X inspector & $\begin{array}{l}-0.60 \\
(1.800)\end{array}$ & $\begin{array}{c}0.22 \\
(1.863)\end{array}$ & $\begin{array}{c}0.89 \\
(1.087)\end{array}$ & $\begin{array}{l}-0.48 \\
(1.500)\end{array}$ & $\begin{array}{c}-1.67 \\
(1.604)\end{array}$ & $\begin{array}{l}-1.50 \\
(2.096)\end{array}$ \\
\hline inspector & $\begin{array}{c}1.21 \\
(3.709)\end{array}$ & $\begin{array}{c}-0.59 \\
(4.303)\end{array}$ & $\begin{array}{l}-2.06 \\
(2.636)\end{array}$ & $\begin{array}{c}1.09 \\
(3.394)\end{array}$ & $\begin{array}{c}3.08 \\
(3.014)\end{array}$ & $\begin{array}{c}2.67 \\
(3.712)\end{array}$ \\
\hline Observations & 27,775 & 27,775 & 27,775 & 27,775 & 27.775 & 27,775 \\
\hline
\end{tabular}

Notes: Standard errors clustered at school level in parentheses: ${ }^{* * *} p<0.01,{ }^{* *} p<0.05,{ }^{*} p<0.1$. Panel A: results on separate regressions for the samples of students attending schools that do and do not have other schools in competition within 30 minutes driving distance. Panel B: results on separate regressions for the samples of low socio-economic background students (average school level escs index below zero) and high socio-economic background students (escs above zero). Panel C: results on inspector is a dummy equal to one if there is an external inspector randomly assigned by Invalsi to invigilate students during the test and help to compute results and documentation relative to the test. For all these specifications, the set of additional controls is identical to those included in Table 4 , results not reported but available upon request. See also Notes to Table 4 for additional details regarding control variables. 
Table 7: Interaction with tenure

\begin{tabular}{|c|c|c|c|c|c|c|}
\hline $\begin{array}{l}\text { Dependent Variable } \\
\text { Test results (Math) }\end{array}$ & $\begin{array}{c}(1) \\
\text { Management }\end{array}$ & $\begin{array}{c}(2) \\
\text { Leadership }\end{array}$ & $\begin{array}{c}(3) \\
\text { Operations }\end{array}$ & $\begin{array}{c}(4) \\
\text { Monitoring }\end{array}$ & $\begin{array}{c}(5) \\
\text { Targets }\end{array}$ & $\begin{array}{c}(6) \\
\text { People }\end{array}$ \\
\hline managerial practices & $\begin{array}{l}4.41^{* *} \\
(1.83)\end{array}$ & $\begin{array}{c}4.87^{* * *} \\
(1.56)\end{array}$ & $\begin{array}{l}2.77^{* *} \\
(1.25)\end{array}$ & $\begin{array}{l}3.89 * * * \\
(1.32)\end{array}$ & $\begin{array}{c}2.77 \\
(1.71)\end{array}$ & $\begin{array}{l}2.00 \\
(2.05)\end{array}$ \\
\hline managerial $\mathrm{X}$ tenure & $\begin{array}{l}-0.36 \\
(0.22)\end{array}$ & $\begin{array}{l}-0.32^{*} \\
(0.17)\end{array}$ & $\begin{array}{l}-0.27 \\
(0.18)\end{array}$ & $\begin{array}{l}-0.26^{*} \\
(0.14)\end{array}$ & $\begin{array}{l}-0.31 \\
(0.20)\end{array}$ & $\begin{array}{l}-0.19 \\
(0.22)\end{array}$ \\
\hline tenure in school & $\begin{array}{c}0.69 \\
(0.42)\end{array}$ & $\begin{array}{l}0.70^{*} \\
(0.37)\end{array}$ & $\begin{array}{c}0.58 \\
(0.37)\end{array}$ & $\begin{array}{l}0.54^{*} \\
(0.31)\end{array}$ & $\begin{array}{c}0.52 \\
(0.33)\end{array}$ & $\begin{array}{c}0.32 \\
(0.38)\end{array}$ \\
\hline principal characteristics & Yes & Yes & Yes & Yes & Yes & Yes \\
\hline school characteristics & Yes & Yes & Yes & Yes & Yes & Yes \\
\hline student characteristics & Yes & Yes & Yes & Yes & Yes & Yes \\
\hline area characteristics & Yes & Yes & Yes & Yes & Yes & Yes \\
\hline regional dummies & Yes & Yes & Yes & Yes & Yes & Yes \\
\hline Observations & 27775 & 27775 & 27775 & 27775 & 27775 & 27775 \\
\hline R-squared & 0.252 & 0.255 & 0.251 & 0.255 & 0.249 & 0.248 \\
\hline
\end{tabular}

Notes: Standard errors clustered at school level in parentheses: $* * * p<0.01,{ }^{* *} p<0.05, * p<0.1$. Tenure is measured in years. The set of additional controls is identical to that included in Table 4: these results are not reported but available upon request.

Table 8: Different sample: excluding pre-2000 reform principals

\begin{tabular}{|c|c|c|c|c|c|c|}
\hline $\begin{array}{l}\text { Dependent Variable } \\
\text { Test results (Math) }\end{array}$ & $\begin{array}{c}(1) \\
\text { Management }\end{array}$ & $\begin{array}{c}(2) \\
\text { Leadership }\end{array}$ & $\begin{array}{c}(3) \\
\text { Operations }\end{array}$ & $\begin{array}{c}(4) \\
\text { Monitoring }\end{array}$ & $\begin{array}{c}(5) \\
\text { Targets }\end{array}$ & $\begin{array}{c}(6) \\
\text { People }\end{array}$ \\
\hline managerial practices & $\begin{array}{c}6.11^{* * *} \\
(1.73)\end{array}$ & $\begin{array}{c}5.24^{* * *} \\
(1.65)\end{array}$ & $\begin{array}{l}2.15^{* *} \\
(1.04)\end{array}$ & $\begin{array}{c}4.80^{* * *} \\
(1.18)\end{array}$ & $\begin{array}{c}5.88 * * * \\
(1.68)\end{array}$ & $\begin{array}{c}5.23^{* * *} \\
(1.94)\end{array}$ \\
\hline principal characteristics & Yes & Yes & Yes & Yes & Yes & Yes \\
\hline school characteristics & Yes & Yes & Yes & Yes & Yes & Yes \\
\hline student characteristics & Yes & Yes & Yes & Yes & Yes & Yes \\
\hline area characteristics & Yes & Yes & Yes & Yes & Yes & Yes \\
\hline regional dummies & Yes & Yes & Yes & Yes & Yes & Yes \\
\hline Observations & 14060 & 14060 & 14060 & 14060 & 14060 & 14060 \\
\hline R-squared & 0.318 & 0.315 & 0.305 & 0.322 & 0.317 & 0.311 \\
\hline
\end{tabular}

Notes: Standard errors clustered at school level in parentheses: ${ }^{* * *} p<0.01,{ }^{* *} p<0.05,{ }^{*} p<0.1$. The sample is composed of principals with 9 (or less) years of experience in post (those appointed post-2000 reform). The set of additional controls is identical to that included in Table 4: these results are not reported but available upon request. 
Table 9: Different institutional constraints

\begin{tabular}{lccc}
\hline \hline $\begin{array}{l}\text { Dependent variable } \\
\text { Test results (Math) }\end{array}$ & $\begin{array}{c}(1) \\
\text { Low constraints }\end{array}$ & $\begin{array}{c}(2) \\
\text { Medium constraints }\end{array}$ & $\begin{array}{c}(3) \\
\text { High constraints }\end{array}$ \\
\hline managerial practices & $2.48^{* *}$ & 1.41 & 0.59 \\
& $(1.16)$ & $(1.08)$ & $(1.56)$ \\
& & & \\
principal characteristics & Yes & Yes & Yes \\
school characteristics & Yes & Yes & Yes \\
student characteristics & Yes & Yes & Yes \\
area characteristics & Yes & Yes & Yes \\
regional dummies & Yes & Yes & Yes \\
& & & \\
Observations & 27775 & 27775 & 27775 \\
R-squared & 0.251 & 0.248 & 0.247 \\
\hline \hline
\end{tabular}

Notes: Standard errors clustered at school level in parentheses: ${ }^{* * *} p<0.01,{ }^{* *} p<0.05,{ }^{*} p<0.1$. A full discussion on how each WMS survey question is classified based on how much SPs activity is likely to be constrained by the institutional setting can be found in Appendix A and see Table A1 for details. The set of additional controls is identical to that included in Table 4: results not reported but available upon request.

Table 10: School level regressions: dispersion measures and percentiles

\begin{tabular}{lcccccc}
\hline \hline & $(1)$ & $(2)$ & $(3)$ & $(4)$ & $(5)$ & $(6)$ \\
& Management & Leadership & $\begin{array}{c}(6) \\
\text { Operations }\end{array}$ & $\begin{array}{c}\text { Monitoring } \\
\text { Targets }\end{array}$ & People \\
\hline row - dep. var. & & & & & & \\
1 - avg test scores & 1.36 & $1.94^{* *}$ & 0.47 & $1.92^{* *}$ & 0.59 & -0.30 \\
& $(1.085)$ & $(0.935)$ & $(0.784)$ & $(0.781)$ & $(1.029)$ & $(1.218)$ \\
2 - 10 pct & 1.27 & $2.19^{* *}$ & 0.27 & $1.44^{*}$ & 1.09 & -0.25 \\
& $(1.133)$ & $(0.974)$ & $(0.819)$ & $(0.820)$ & $(1.072)$ & $(1.270)$ \\
3 - 50 pct & 1.62 & $2.14^{* *}$ & 0.60 & $2.22^{* *}$ & 0.74 & -0.21 \\
& $(1.207)$ & $(1.041)$ & $(0.872)$ & $(0.868)$ & $(1.145)$ & $(1.354)$ \\
$4-90$ pct & 0.96 & 1.33 & 0.22 & $1.87^{* *}$ & -0.11 & -0.40 \\
& $(1.174)$ & $(1.016)$ & $(0.848)$ & $(0.846)$ & $(1.112)$ & $(1.315)$ \\
5 - 90 10 pct diff & -0.31 & -0.86 & -0.04 & 0.43 & -1.20 & -0.15 \\
& $(0.911)$ & $(0.789)$ & $(0.657)$ & $(0.662)$ & $(0.858)$ & $(1.019)$ \\
6 - st dev test scores & -0.09 & -0.31 & -0.03 & 0.18 & -0.40 & -0.01 \\
& $(0.315)$ & $(0.273)$ & $(0.227)$ & $(0.229)$ & $(0.297)$ & $(0.352)$ \\
& & & & & & \\
Observations & 249 & 249 & 249 & 249 & 249 & 249 \\
\hline \hline
\end{tabular}

Notes: Robust standard errors in parentheses: ${ }^{* * *} p<0.01,{ }^{* *} p<0.05,{ }^{*} p<0.1$. Data are aggregated at the school level. Dependent variables are as follows: row 1: average test scores in math; rows 2 to 4: 10th, 50th and 90th percentile of the distribution of test scores; row 5: 90-10 percentile differential in test scores; row 6: standard deviation of the test scores in the same school. The set of additional controls is identical to that included in Table 4: results not reported but available upon request. See Table 2 for additional details regarding control variables. 
Table 11: Baseline model. PISA Data, Italy

\begin{tabular}{|c|c|c|c|c|c|c|}
\hline $\begin{array}{l}\text { Dependent Variable } \\
\text { Test results (Math) }\end{array}$ & $\begin{array}{c}(1) \\
\text { LDRSHP }\end{array}$ & $\begin{array}{c}(2) \\
\text { Curricula }\end{array}$ & $\begin{array}{c}(3) \\
\text { Resources }\end{array}$ & $\begin{array}{c}(4) \\
\text { Leadership }\end{array}$ & $\begin{array}{c}(5) \\
\text { Operations }\end{array}$ & $\begin{array}{c}(6) \\
\text { Monitoring } \\
\end{array}$ \\
\hline managerial practices & $\begin{array}{c}-0.45 \\
(1.841)\end{array}$ & $\begin{array}{c}-0.48 \\
(2.056)\end{array}$ & $\begin{array}{c}-4.35 \\
(4.304)\end{array}$ & $\begin{array}{c}4.70 \\
(3.645)\end{array}$ & $\begin{array}{c}-4.30 \\
(4.269)\end{array}$ & $\begin{array}{c}1.31 \\
(3.484)\end{array}$ \\
\hline competition (two or more schools) & $\begin{array}{c}-3.32 \\
(6.648)\end{array}$ & $\begin{array}{l}-3.30 \\
(6.541)\end{array}$ & $\begin{array}{c}-2.27 \\
(4.053)\end{array}$ & $\begin{array}{c}-3.85 \\
(6.627)\end{array}$ & $\begin{array}{c}-3.37 \\
(6.686)\end{array}$ & $\begin{array}{c}-3.52 \\
(6.638)\end{array}$ \\
\hline competition (one school) & $\begin{array}{l}-11.77 \\
(8.263)\end{array}$ & $\begin{array}{l}-11.68 \\
(8.118)\end{array}$ & $\begin{array}{c}-6.12 \\
(5.027)\end{array}$ & $\begin{array}{l}-11.79 \\
(8.228)\end{array}$ & $\begin{array}{l}-11.88 \\
(8.319)\end{array}$ & $\begin{array}{l}-11.87 \\
(8.250)\end{array}$ \\
\hline school size & $\begin{array}{l}9.22^{* * *} \\
(3.397)\end{array}$ & $\begin{array}{l}9.19^{* * *} \\
(3.427)\end{array}$ & $\begin{array}{c}10.59^{* * *} \\
(2.668)\end{array}$ & $\begin{array}{l}9.17^{* * *} \\
(3.386)\end{array}$ & $\begin{array}{l}9.20^{* * *} \\
(3.380)\end{array}$ & $\begin{array}{l}9.27^{* * *} \\
(3.407)\end{array}$ \\
\hline private school & $\begin{array}{c}-40.71^{* * *} \\
(13.022)\end{array}$ & $\begin{array}{c}-40.90^{* * *} \\
(13.068)\end{array}$ & $\begin{array}{l}-15.22 \\
(9.730)\end{array}$ & $\begin{array}{c}-40.77^{* * *} \\
(13.114)\end{array}$ & $\begin{array}{c}-40.56 * * * \\
(12.930)\end{array}$ & $\begin{array}{c}-40.89 * * * \\
(13.071)\end{array}$ \\
\hline share part-time teachers & $\begin{array}{c}6.84 \\
(19.335)\end{array}$ & $\begin{array}{c}7.05 \\
(19.361)\end{array}$ & $\begin{array}{c}13.21 \\
(11.501)\end{array}$ & $\begin{array}{c}6.96 \\
(19.422)\end{array}$ & $\begin{array}{c}6.78 \\
(19.250)\end{array}$ & $\begin{array}{c}7.21 \\
(19.419)\end{array}$ \\
\hline socio_economic background & $\begin{array}{l}7.24^{* * *} \\
(0.913)\end{array}$ & $\begin{array}{l}7.24^{* * *} \\
(0.914)\end{array}$ & $\begin{array}{l}8.33^{* * *} \\
(0.723)\end{array}$ & $\begin{array}{l}7.22^{* * *} \\
(0.912)\end{array}$ & $\begin{array}{l}7.25^{* * *} \\
(0.912)\end{array}$ & $\begin{array}{l}7.23^{* * *} \\
(0.914)\end{array}$ \\
\hline immigrant student, 1st gen. & $\begin{array}{c}-39.96^{* * *} \\
(3.324)\end{array}$ & $\begin{array}{c}-39.96^{* * *} \\
(3.318)\end{array}$ & $\begin{array}{c}-36.48^{* * *} \\
(2.632)\end{array}$ & $\begin{array}{c}-39.97 * * * \\
(3.325)\end{array}$ & $\begin{array}{c}-40.03^{* * *} \\
(3.320)\end{array}$ & $\begin{array}{c}-39.91^{* * *} \\
(3.330)\end{array}$ \\
\hline immigrant student, 2nd gen. & $\begin{array}{c}-23.73^{* * *} \\
(5.862)\end{array}$ & $\begin{array}{c}-23.78^{* * *} \\
(5.884)\end{array}$ & $\begin{array}{c}-15.75^{* * *} \\
(4.106)\end{array}$ & $\begin{array}{c}-23.98^{* * *} \\
(5.869)\end{array}$ & $\begin{array}{c}-23.66^{* * *} \\
(5.852)\end{array}$ & $\begin{array}{c}-23.84^{* * *} \\
(5.872)\end{array}$ \\
\hline gender student (female $=1$ ) & $\begin{array}{c}-31.94^{* * *} \\
(1.868)\end{array}$ & $\begin{array}{c}-31.92^{* * *} \\
(1.881)\end{array}$ & $\begin{array}{c}-31.43^{* * *} \\
(1.426)\end{array}$ & $\begin{array}{c}-31.87^{* * *} \\
(1.873)\end{array}$ & $\begin{array}{c}-32.00^{* * *} \\
(1.868)\end{array}$ & $\begin{array}{c}-31.88 * * * \\
(1.865)\end{array}$ \\
\hline student behind & $\begin{array}{c}-42.79^{* * *} \\
(2.073)\end{array}$ & $\begin{array}{c}-42.80^{* * *} \\
(2.070)\end{array}$ & $\begin{array}{c}-48.44^{* * *} \\
(1.549)\end{array}$ & $\begin{array}{c}-42.80^{* * *} \\
(2.068)\end{array}$ & $\begin{array}{c}-42.80 * * * \\
(2.072)\end{array}$ & $\begin{array}{c}-42.78^{* * *} \\
(2.070)\end{array}$ \\
\hline dummy village or rural area & $\begin{array}{c}12.29 \\
(10.989)\end{array}$ & $\begin{array}{c}12.31 \\
(11.039)\end{array}$ & $\begin{array}{c}11.72 \\
(10.432)\end{array}$ & $\begin{array}{c}11.48 \\
(10.919)\end{array}$ & $\begin{array}{c}13.10 \\
(11.049)\end{array}$ & $\begin{array}{c}11.71 \\
(10.859)\end{array}$ \\
\hline dummy small town & $\begin{array}{c}5.51 \\
(9.358)\end{array}$ & $\begin{array}{c}5.39 \\
(9.295)\end{array}$ & $\begin{array}{c}4.14 \\
(8.948)\end{array}$ & $\begin{array}{c}5.24 \\
(9.310)\end{array}$ & $\begin{array}{c}5.38 \\
(9.304)\end{array}$ & $\begin{array}{c}5.13 \\
(9.375)\end{array}$ \\
\hline dummy town & $\begin{array}{c}2.53 \\
(7.831)\end{array}$ & $\begin{array}{c}2.38 \\
(7.763)\end{array}$ & $\begin{array}{c}1.28 \\
(8.284)\end{array}$ & $\begin{array}{c}2.29 \\
(7.748)\end{array}$ & $\begin{array}{c}2.73 \\
(7.785)\end{array}$ & $\begin{array}{c}2.13 \\
(7.840)\end{array}$ \\
\hline dummy city & $\begin{array}{c}-6.01 \\
(8.672)\end{array}$ & $\begin{array}{c}-6.03 \\
(8.654)\end{array}$ & $\begin{array}{c}-2.87 \\
(8.814)\end{array}$ & $\begin{array}{c}-5.82 \\
(8.631)\end{array}$ & $\begin{array}{c}-6.20 \\
(8.692)\end{array}$ & $\begin{array}{c}-6.12 \\
(8.676)\end{array}$ \\
\hline Constant & $\begin{array}{c}384.95^{* * * *} \\
(22.094)\end{array}$ & $\begin{array}{c}345.05^{* * *} \\
(21.071)\end{array}$ & $\begin{array}{c}447.48^{* * *} \\
(19.937)\end{array}$ & $\begin{array}{c}367.92^{* * *} \\
(26.087)\end{array}$ & $\begin{array}{c}400.05^{* * *} \\
(26.679)\end{array}$ & $\begin{array}{c}380.43^{* * *} \\
(25.200)\end{array}$ \\
\hline Observations & 24,882 & 24,915 & 24,915 & 24,882 & 24,882 & 24,882 \\
\hline R-squared & 0.434 & 0.434 & 0.405 & 0.434 & 0.434 & 0.434 \\
\hline
\end{tabular}

Notes: Robust standard errors in parentheses: ${ }^{* * *} p<0.01,{ }^{*} p<0.05,{ }^{*} p<0.1$. Dependent variable is standardized test score in mathematics. Managerial practices are as follows: in cols.1-3 we use the variables LDRSHP, RESPCUR, RESPRES as in the OECD PISA dataset, in col.4 we use the average of items (a), (k) and (l) of Q26 to construct the Leadership indicator, in col. 5 items (b), (c), (e), (h), (j) and (m) for Operations indicator, in col.6 (d), (f), (g) and (i) for Monitoring indicator. Competition is the number of schools in competition (no competition is the omitted dummy). School size is the natural logarithm of the number of students in school. Private is a dummy equal to one for private schools. Immigrant student 1st generation are students born abroad of foreign-born parents, immigrant student 2 nd generation are native-born children of foreign-born parents. Student behind is a dummy equal to 1 if the student has repeated a grade. Dummies for urbanization are defined in Table (large city is the omitted category). Regional and school type dummies included. 
Table 12: Baseline model. PISA Data, 33 OECD Countries

\begin{tabular}{|c|c|c|c|c|c|c|}
\hline $\begin{array}{l}\text { Dependent Variable } \\
\text { Test results (Math) }\end{array}$ & $\begin{array}{c}(1) \\
\text { LDRSHP }\end{array}$ & $\begin{array}{c}(2) \\
\text { Curricula }\end{array}$ & $\begin{array}{c}(3) \\
\text { Resources } \\
\end{array}$ & $\begin{array}{c}(4) \\
\text { Leadership }\end{array}$ & $\begin{array}{c}(5) \\
\text { Operations }\end{array}$ & $\begin{array}{c}(6) \\
\text { Monitoring } \\
\end{array}$ \\
\hline managerial practices & $\begin{array}{l}-2.29^{*} \\
(1.380)\end{array}$ & $\begin{array}{c}-1.03 \\
(1.666)\end{array}$ & $\begin{array}{c}-0.46 \\
(2.258)\end{array}$ & $\begin{array}{c}-2.40 \\
(2.549)\end{array}$ & $\begin{array}{l}-6.53^{* *} \\
(3.280)\end{array}$ & $\begin{array}{l}-2.08 \\
(2.543)\end{array}$ \\
\hline competition (two or more schools) & $\begin{array}{l}9.69^{* * *} \\
(2.825)\end{array}$ & $\begin{array}{l}9.27^{* * *} \\
(2.858)\end{array}$ & $\begin{array}{l}9.39 * * * \\
(2.879)\end{array}$ & $\begin{array}{l}9.57^{* * *} \\
(2.836)\end{array}$ & $\begin{array}{l}9.55^{* * *} \\
(2.827)\end{array}$ & $\begin{array}{l}9.55^{* * *} \\
(2.861)\end{array}$ \\
\hline competition (one school) & $\begin{array}{c}10.44^{* * * *} \\
(2.886)\end{array}$ & $\begin{array}{c}10.30 * * * \\
(2.911)\end{array}$ & $\begin{array}{c}10.33^{* * *} \\
(2.935)\end{array}$ & $\begin{array}{c}10.36^{* * *} \\
(2.898)\end{array}$ & $\begin{array}{c}10.32^{* * *} \\
(2.904)\end{array}$ & $\begin{array}{c}10.35^{* * *} \\
(2.907)\end{array}$ \\
\hline school size & $\begin{array}{c}13.35 * * * \\
(2.095)\end{array}$ & $\begin{array}{c}13.19^{* * *} \\
(2.142)\end{array}$ & $\begin{array}{c}13.25^{* * *} \\
(2.105)\end{array}$ & $\begin{array}{c}13.28^{* * *} \\
(2.127)\end{array}$ & $\begin{array}{c}13.44^{* * *} \\
(2.052)\end{array}$ & $\begin{array}{c}13.29 * * * \\
(2.119)\end{array}$ \\
\hline private school & $\begin{array}{l}9.36^{* *} \\
(4.312)\end{array}$ & $\begin{array}{l}9.74^{* *} \\
(4.584)\end{array}$ & $\begin{array}{c}9.81^{*} \\
(5.734)\end{array}$ & $\begin{array}{l}9.43^{* *} \\
(4.363)\end{array}$ & $\begin{array}{l}9.09 * * \\
(4.200)\end{array}$ & $\begin{array}{l}9.20^{* *} \\
(4.274)\end{array}$ \\
\hline share part-time teachers & $\begin{array}{c}16.40^{* * *} \\
(5.925)\end{array}$ & $\begin{array}{c}16.88^{* * *} \\
(5.908)\end{array}$ & $\begin{array}{c}16.95 * * * \\
(5.953)\end{array}$ & $\begin{array}{c}16.97 * * * \\
(5.976)\end{array}$ & $\begin{array}{c}16.48^{* * * *} \\
(5.870)\end{array}$ & $\begin{array}{c}16.69^{* * *} \\
(5.960)\end{array}$ \\
\hline socio_economic background & $\begin{array}{c}30.26^{* * *} \\
(0.733)\end{array}$ & $\begin{array}{c}30.27 * * * \\
(0.737)\end{array}$ & $\begin{array}{c}30.25^{* * *} \\
(0.737)\end{array}$ & $\begin{array}{c}30.25^{* * *} \\
(0.734)\end{array}$ & $\begin{array}{c}30.25^{* * *} \\
(0.729)\end{array}$ & $\begin{array}{c}30.25^{* * *} \\
(0.735)\end{array}$ \\
\hline immigrant student, 1st gen. & $\begin{array}{c}-12.15^{* * *} \\
(2.667)\end{array}$ & $\begin{array}{c}-12.09 * * * \\
(2.708)\end{array}$ & $\begin{array}{c}-12.06 * * * \\
(2.707)\end{array}$ & $\begin{array}{c}-12.03^{* * *} \\
(2.689)\end{array}$ & $\begin{array}{c}-12.14^{* * *} \\
(2.681)\end{array}$ & $\begin{array}{c}-12.07^{* * *} \\
(2.679)\end{array}$ \\
\hline immigrant student, 2nd gen. & $\begin{array}{c}-13.09 * * * \\
(2.261)\end{array}$ & $\begin{array}{c}-12.97 * * * \\
(2.301)\end{array}$ & $\begin{array}{c}-12.96 * * * \\
(2.278)\end{array}$ & $\begin{array}{c}-12.99 * * * \\
(2.297)\end{array}$ & $\begin{array}{c}-12.96^{* * *} \\
(2.259)\end{array}$ & $\begin{array}{c}-13.00^{* * *} \\
(2.298)\end{array}$ \\
\hline gender student (female $=1$ ) & $\begin{array}{c}-17.56^{* * *} \\
(1.051)\end{array}$ & $\begin{array}{c}-17.52^{* * *} \\
(1.047)\end{array}$ & $\begin{array}{c}-17.51^{* * *} \\
(1.040)\end{array}$ & $\begin{array}{c}-17.53^{* * *} \\
(1.048)\end{array}$ & $\begin{array}{c}-17.56^{* * *} \\
(1.048)\end{array}$ & $\begin{array}{c}-17.54^{* * *} \\
(1.052)\end{array}$ \\
\hline student behind & $\begin{array}{c}-67.70^{* * *} \\
(1.533)\end{array}$ & $\begin{array}{c}-67.78^{* * *} \\
(1.531)\end{array}$ & $\begin{array}{c}-67.74^{* * *} \\
(1.537)\end{array}$ & $\begin{array}{c}-67.74^{* * *} \\
(1.542)\end{array}$ & $\begin{array}{c}-67.76^{* * *} \\
(1.520)\end{array}$ & $\begin{array}{c}-67.71^{* * *} \\
(1.544)\end{array}$ \\
\hline dummy village or rural area & $\begin{array}{c}9.54^{*} \\
(5.479)\end{array}$ & $\begin{array}{c}9.47^{*} \\
(5.500)\end{array}$ & $\begin{array}{c}9.50^{*} \\
(5.489)\end{array}$ & $\begin{array}{c}9.53^{*} \\
(5.487)\end{array}$ & $\begin{array}{c}9.36^{*} \\
(5.497)\end{array}$ & $\begin{array}{c}9.63^{*} \\
(5.466)\end{array}$ \\
\hline dummy small town & $\begin{array}{c}6.30^{*} \\
(3.766)\end{array}$ & $\begin{array}{c}5.94 \\
(3.807)\end{array}$ & $\begin{array}{c}6.08 \\
(3.776)\end{array}$ & $\begin{array}{c}6.28^{*} \\
(3.757)\end{array}$ & $\begin{array}{c}6.32^{*} \\
(3.759)\end{array}$ & $\begin{array}{c}6.19 \\
(3.773)\end{array}$ \\
\hline dummy town & $\begin{array}{c}4.48 \\
(3.414)\end{array}$ & $\begin{array}{c}4.33 \\
(3.447)\end{array}$ & $\begin{array}{c}4.40 \\
(3.437)\end{array}$ & $\begin{array}{c}4.53 \\
(3.422)\end{array}$ & $\begin{array}{c}4.41 \\
(3.406)\end{array}$ & $\begin{array}{c}4.50 \\
(3.422)\end{array}$ \\
\hline dummy city & $\begin{array}{c}3.94 \\
(3.576)\end{array}$ & $\begin{array}{c}3.89 \\
(3.602)\end{array}$ & $\begin{array}{c}3.91 \\
(3.537)\end{array}$ & $\begin{array}{c}4.02 \\
(3.604)\end{array}$ & $\begin{array}{c}3.86 \\
(3.543)\end{array}$ & $\begin{array}{c}3.97 \\
(3.599)\end{array}$ \\
\hline Constant & $\begin{array}{c}407.45^{* * * *} \\
(17.004)\end{array}$ & $\begin{array}{c}404.03^{* * *} \\
(14.439)\end{array}$ & $\begin{array}{c}403.29^{* * * *} \\
(13.987)\end{array}$ & $\begin{array}{c}415.84^{* * *} \\
(18.102)\end{array}$ & $\begin{array}{c}426.05^{* * * *} \\
(20.791)\end{array}$ & $\begin{array}{c}408.93^{* * *} \\
(16.505)\end{array}$ \\
\hline Observations & 242,978 & 243,543 & 243,543 & 242,978 & 242,955 & 242,919 \\
\hline R-squared & 0.347 & 0.346 & 0.346 & 0.346 & 0.347 & 0.346 \\
\hline
\end{tabular}

Notes: Robust standard errors in parentheses: ${ }^{* * *} p<0.01,{ }^{*} p<0.05,{ }^{*} p<0.1$. Dependent variable is standardized test score in mathematics. Managerial practices are as follows: in cols.1-3 we use the variables LDRSHP, RESPCUR, RESPRES as in the OECD PISA dataset, in col.4 we use items (a), (k) and (l) of Q26 to construct the Leadership indicator, in col. 5 items (b), (c), (e), (h), (j) and (m) for Operations indicator, in col.6 (d), (f), (g) and (i) for Monitoring indicator. Competition is the number of schools in competition (no competition is the omitted dummy). School size is the natural logarithm of the number of students in school. Private is a dummy equal to one for private schools. Immigrant student 1st generation are students born abroad of foreign-born parents, immigrant student 2nd generation are native-born children of foreign-born parents. Student behind is a dummy equal to 1 if the student has repeated a grade. Dummies for urbanization are defined in Table (large city dummy is the omitted category). All regressions include country dummies. 


\section{A Cross country comparisons for individual questions of the survey}

In Section 4 we discussed how different areas of management are influenced by institutional constraints and we claimed that the delay of Italy with respect to other countries is not completely attributable to such constraints. In this Appendix we explain in more detail how we classify both the single survey questions and the different areas of management based on how much SPs activity is likely to be constrained by the institutional setting. The idea is that, if the lower scores on managerial practices of Italian SPs were mainly due to its institutional setting, then we should expect that Italy's lowest relative scores are in those questions and sections where constraints are more binding while, conversely, in managerial practices where constraints are less binding, we should expect that Italian SPs scores are more similar to that observed in other countries. In other words, if the distance from other countries does not vary systematically with the importance of institutional constraints, then the evidence would suggest that the lower performance of Italian SPs cannot be fully explained by differences in institutional settings.

This classification can also be used to compare the performance of the Italian SPs with that of other countries. We start checking if the Italian data are closer to that of Germany the country where, according to existing evidence, both education and public sector institutional settings are relatively more similar to the Italian one, compared to the UK or the US (Pont et al., 2008). In general, Anglo-Saxon legal systems, based on common law, are less subject to institutional constraints and bureaucratic procedures, while our two remaining countries have more complex institutional settings. Existing evidence indicates a lack of autonomy of Canadian SPs during the process of personnel selection, while Swedish SPs seem able to affect more significantly the selection of the teaching staff. Overall, the reality experienced by Swedish SPs seems closer to the one of the Anglo-Saxons, in contrast to Canada where the institutional system has characteristics more similar to those of Germany and Italy.

Second, we focus on the different areas of management. In most countries schools are dominated by the public sector, with a strong union representation, and tend to be particularly poor in certain areas of human resource management such as promoting and rewarding high performing and/or firing badly performing teachers (Bloom et al., 2012; Pont et al., 2008). In fact, we expect People being the area of management where institutional factors are more binding in some countries than others. Therefore, if the presence of constraints were the main explanation for the Italian gap in managerial practices, People should be the area showing the largest gap between Italy and the other countries, particularly the Anglo-Saxon ones. On the other hand, areas as Monitoring and Targets, that capture other aspects of managerial ability, as the capacity of identifying and communicating targets, or monitoring performance and reviewing results, should be less subject to such institutional constraints.

Third, we focus on the single questions results. In particular, for each question of our survey, Table A1 shows the index numbers using Italy as reference (Italy $=100$ ). All values are then easily interpretable in terms of percentage deviations. That is, for the first question on Leadership vision a value of 130 for Canada, implies that Canadian SPs managerial practices obtain a score $30 \%$ higher than the Italian SPs. First of all, this Table always shows values higher than 100. Thus, a first clear evidence is that, compared to the other five countries analyzed here, the Italian SPs managerial practices always obtain lower scores. In the last column of the Table we also classify each question on a scale from 1 (low constraints) 
to 3 (highest institutional constraints). ${ }^{54}$

In detail, numbers indicate that the distance reported by Italian SPs in the incentives (People) section is smaller than that found the other areas of management. Remember that People is the managerial area where institutional constraints are more binding and where the score is lower in all countries. Conversely, Target is the area where Italian performance is relatively worse while institutional constraints are not significantly binding. In this case, our index numbers vary from a minimum of 140 (compared to Germany) to 167 (UK). In general, the analysis of the scores of the different sections does not seem to show any systematic relationship between the importance of institutional constraints and the relative performance of Italy. ${ }^{55}$ When we focus on single questions scores we confirm the previous analysis and find additional interesting evidence. For example, in question 18 on "Rewarding High Performers" (People), which mainly concerns on how SPs identify and promote more talented teachers and where institutional constraints are considered more stringent, index numbers show that the Italian SPs' scores are much lower than in Germany (almost 44\%), while they are $81 \%$ lower than in UK schools. In turn, in question 17 on Clarity and Comparability of Targets, an area in which the institutional constraints are very low, if not absent, Italian SPs are equally distant from SPs in other countries, with a gap in scores that varies from about 40\% (Germany, Sweden and the US) to about $60 \%$ (the UK).

As a final check, we use our classification of institutional constraint to calculate the correlation between the former and the index numbers reported in Table A1. Indeed, if the differences between Italy and the other countries were mainly due to institutional constraints we should find a positive correlation. Conversely, consistently with what we have seen before, we find a negative correlation (-0.22): as the institutional constraints become more binding, the distance of Italy from the other countries appears to be lower rather than higher. In other words, a greater freedom of action in favor of the SPs is related to a lower relative quality of the management, and this negative correlation is even stronger for Italian SPs when compared with those of other countries with similar institutional setting (-0.41 and -0.25 with Canada and Germany respectively). ${ }^{56}$ Also in this case, if the key determinant of the performance of SPs was the Italian institutional framework we would expect the opposite result.

In sum, this evidence shows that institutional constraints cannot fully explain the observed cross countries heterogeneity in managerial SPs activities and the low scores of Italian SPs. Indeed, even when answering to questions where institutional constraints are hardly binding, the distance of the Italian results from those reported by other countries SPs remains significant.

\footnotetext{
${ }^{54}$ It is fair to say that this classification process involves an unavoidable degree of arbitrariness. It is based, however, on the experience accumulated during the data collection phase, in which we discussed with the SPs for a total of about 600 hours.

${ }^{55}$ In order to control for the goodness of our classification, we have also selected our Italian sample and we have calculated the (within country) standard deviation for each of our 23 questions. In this case, we expect that when institutional constraints are more stringent there is also less variability of performance across the Italian SPs. Our data confirm this hypothesis: they indicate a smaller heterogeneity (standard deviation equal to 0.49 ) for the section People, for Targets the standard deviation is equal to 0.54 , while it has the highest variability for the Operations and Monitoring sections (about 0.68).

${ }^{56}$ The value of the correlation coefficient is reduced but remains negative even when we compare Italy than in countries where institutional constraints are less stringent (Sweden, United Kingdom and United States).
} 


\section{B Selection of the Sample and Attrition}

The original universe of Italian secondary schools comprises 5,125 schools. From the universe, we extracted a $16.5 \%$ random sample of schools (848) that is representative of the population of upper secondary schools, and it is stratified by macro area (North-west, North-east, Center, South) and type of school (Lyceum, Vocational and Technical). From this sample, we dropped about $20 \%$ of schools that were not eligible to participate in the survey for different reasons, the two most important being the SP was too recently appointed (less than 1 year) and the number of students was below the 50 students threshold used in the WMS. The remaining sample of eligible schools comprises $56.6 \%$ of schools interviewed, $28.7 \%$ of schools contacted that did not refuse to participate in the survey but that could not be interviewed because the survey ended before these SPs could be recalled, and $14.7 \%$ of schools that explicitly refused to grant the interview. The main reasons for refusals being that SPs were time constrained and their skepticism about this type of surveys.

Unfortunately, available data for the sample of SPs that refused the interview is limited to very few basic variables: ownership (private vs public), type of school, and location. In order to address the possibility of non-random attrition in survey data, we decided to recall the SPs that refused in the first place. For a subsample of 41 (out of 94) SPs we were able to obtain additional information on relevant demographic and school characteristics and we compared this subsample of refusals with the sample of SPs that granted the interview. Demographic characteristics are very similar, the average age of SPs of the those interviewed is about 58.6 years, against about 57.9 for those that refused to grant the interview; we found a small difference in terms of tenure, 6.5 years for the sample of interviewed against 7.2 for those that refused, suggesting that recently appointed SPs are more keen to this type of surveys.

Observable school characteristics are also quite similar across the two samples: the average number of students is 618 for participants in the survey and 525 for refusals. The latter are more concentrated in private schools and in the Southern regions of Italy, with about $46 \%$ of the overall number of refusals (against $38 \%$ for participants). Finally, the distribution of school type on the basis of the curriculum offered shows that most of the refusals are in the Lyceums (about 42\%) and in Technical schools (37\%), while the corresponding numbers for the sample of those that participate in the survey are $37 \%$ and $20 \%$ respectively. 
Table A1: Index Numbers and Institutional Constraints

\begin{tabular}{|c|c|c|c|c|c|c|c|}
\hline & & Canada & Germany & Sweden & $\overline{\mathrm{UK}}$ & $\overline{\mathrm{US}}$ & Constraint \\
\hline 1 & Leadership vision & 129.72 & 112.02 & 103.81 & 126.23 & 118.54 & 1 \\
\hline 2 & Standardisation of Instructional Processes & 131.48 & 125.56 & 107.22 & 127.38 & 130.44 & 2 \\
\hline 3 & Personalization of Instruction and Learning & 146.19 & 121.93 & 166.00 & 132.75 & 133.81 & 2 \\
\hline 4 & Data-Driven Planning and Student Transitions & 138.20 & 115.29 & 124.79 & 150.45 & 131.37 & 1 \\
\hline 5 & Adopting Educational Best Practices & 154.66 & 141.61 & 133.62 & 148.49 & 147.80 & 1 \\
\hline 6 & Continuous Improvement & 135.44 & 130.07 & 142.97 & 145.96 & 132.96 & 1 \\
\hline 7 & Performance Tracking & 140.62 & 122.73 & 154.28 & 144.74 & 139.43 & 1 \\
\hline 8 & Performance Review & 137.40 & 122.83 & 141.48 & 145.12 & 136.31 & 1 \\
\hline 9 & Performance Dialogue & 150.44 & 139.86 & 164.88 & 156.66 & 143.97 & 1 \\
\hline 10 & Consequence Management & 118.48 & 115.58 & 120.40 & 127.05 & 121.08 & 2 \\
\hline 11 & Target Balance & 159.73 & 134.16 & 160.73 & 160.24 & 144.55 & 2 \\
\hline 12 & Target Inter-Connection & 186.79 & 150.50 & 191.57 & 194.71 & 164.99 & 1 \\
\hline 13 & Time Horizon of Targets & 157.41 & 140.01 & 132.33 & 161.58 & 146.32 & 1 \\
\hline 14 & Target Stretch & 153.69 & 134.35 & 141.45 & 158.68 & 143.08 & 1 \\
\hline 15 & Clearly Defined Accountability for School Leaders & 140.88 & 136.05 & 146.53 & 151.11 & 148.34 & 2 \\
\hline 16 & Clearly Defined Leadership and Teacher Roles & 136.82 & 124.88 & 135.54 & 152.50 & 128.77 & 2 \\
\hline 17 & Clarity and Comparability of Targets & 150.68 & 145.06 & 144.76 & 163.20 & 142.25 & 1 \\
\hline 18 & Rewarding High Performers & 155.67 & 143.78 & 155.65 & 181.78 & 169.14 & 3 \\
\hline 19 & Removing Poor Performers & 105.39 & 130.44 & 174.87 & 136.37 & 118.63 & 3 \\
\hline 20 & Promoting High Performers & 109.01 & 111.52 & 132.52 & 142.54 & 140.34 & 3 \\
\hline 21 & Managing Talent & 145.39 & 111.65 & 112.77 & 174.21 & 139.46 & 3 \\
\hline 22 & Retaining talent & 138.26 & 131.90 & 122.16 & 140.51 & 128.84 & 3 \\
\hline \multirow[t]{7}{*}{23} & Creating a Distinctive Employee Value Proposition & 105.34 & 108.03 & 125.36 & 125.35 & 113.02 & 2 \\
\hline & Leadership & 135.23 & 123.10 & 126.39 & 141.57 & 130.47 & \\
\hline & Operations & 142.48 & 125.72 & 133.25 & 139.74 & 135.63 & \\
\hline & Monitoring & 136.10 & 125.83 & 144.26 & 143.54 & 134.51 & \\
\hline & Targets & 161.34 & 140.60 & 153.56 & 167.28 & 148.02 & \\
\hline & People & 126.40 & 122.81 & 136.02 & 149.04 & 134.28 & \\
\hline & Management & 139.80 & 127.36 & 139.30 & 147.26 & 136.32 & \\
\hline
\end{tabular}

Notes: Each value in the Table is equal to (value country/value Italy)*100. Management is the average score calculated using all questions, Leadership is the average for questions 1, 15 and 16; Operations is the average for questions 2 to 5, Monitoring is the average for questions 6 to 10 ; Targets is the average for questions 11 to 14 and 17 People is the average for questions 18 to 23 . See Notes to Table A2 for more details concerning the sections and questions of the survey. 
Table A2: Questions of the World Management Survey

Leadership: "Clearly defined accountability for leaders"

Leadership: "Clearly def. leadership and teacher roles"

Operations: "Standardisation of instructional processes"
Questions

Q1. A) What is the schools vision for the next five years? Do teachers/ staff know and understand the vision? B) Who does your school consider to be your key stakeholders? How is this vision communicated to the overall school community? C) Who is involved in setting this vision/ strategy? When there is disagreement, how does the school leader build alignment?

Q15. A) Who is accountable for delivering on school targets? B) How are individual school leaders held responsible for the delivery of targets? Does this apply to equity and cost targets as well as quality targets? C) What authority do you have to impact factors that would allow them to meet those targets (e.g. budgetary authority, hiring and firing)? Is this sufficient?

Q16. A) How are the roles and responsibilities of the school leader defined? How are they linked to student outcomes/ performance? B) How are leadership responsibilities distributed across individuals and teams within the school? C) How are the roles and responsibilities of the teachers defined? How clearly are required teaching competences defined and communicated? D) How are these linked to student outcomes/ performance?

Q2. A) How structured or standardized are the instructional planning processes across the school? B) What tools and resources are provided to teachers (e.g. standards-based lesson plans and textbooks) to ensure consistent level of quality in delivery across classrooms? C) What are the expectations for the use of these resources and techniques? D) How does the school leader monitor and ensure consistency in quality across classrooms? 
Continuation of Table A2

Operations: "Personalization of Instruction and Learning"

Q3. A) How much does the school attempt to identify individual student needs? B) How are these needs accommodated for within the classroom? How do you as a school leader ensure that teachers are effective in personalising instruction in each classroom across the school? C) What about students, how does the school ensure they are engaged in their own learning? How are parents incorporated in this process?

Operations: "Data-Driven Planning and Student Transitions" Q4. A) Is data used to inform planning and strategies? If so how is it used especially in regards to student transitions through grades/ levels? B) What drove the move towards more data-driven planning/ tracking?

Operations: "Adopting Educational Best Practices" Q5. A) How does the school encourage incorporating new teaching practices into the classroom? B) How are these learning or new teaching practices shared across teachers? What about across grades or subjects? How does sharing happen across schools (community, statewide etc), if at all? C) How does the school ensure that teachers are utilising these new practices in the classroom? How often does this happen?

Monitoring: "Continuous Improvement"

Q6. A) When problems (e.g. within school/ teaching tactics/ etc.) do occur, how do they typically get exposed and fixed? B) Can you talk me through the process for a recent problem that you faced? C) Who within the school gets involved in changing or improving process? How do the different staff groups get involved in this? D) Does the staff ever suggest process improvements? 
Continuation of Table A2

Monitoring: "Performance Tracking"

Monitoring: "Performance Review"

Monitoring: "Performance Dialogue"

Monitoring: "Consequence Management"

Targets: "Target Balance"

Q11. A) What types of targets are set for the school to improve student outcomes? Which staff levels are held accountable to achieve these stated goals? B) How much are these targets determined by external factors? Can you tell me about goals that are not externally set for the school (e.g. by the government or regulators)? 
Continuation of Table A2

Targets: "Target Inter-Connection"

Q12. A) How are these goals cascaded down to the different staff groups or to individual staff members? B) How are your targets linked to the overall school-system

Targets: "Time Horizon of Targets"

Targets: "Target Stretch"

Targets: "Clarity and Comparability of Targets"

People: "Rewarding High Performers" performance and its goals?

Q13. A) What kind of time scale are you looking at with your targets? B) Which goals receive the most emphasis? C) Are the long-term and short-term goals set independently? D) Could you meet all your short-run goals but miss your long-run goals?

Q14. A) How tough are your targets? How pushed are you by the targets? B) On average, how often would you say that you and your school meet its targets? How are your targets benchmarked? C) Do you feel that on targets all departments/ areas receive the same degree of difficulty? Do some departments/ areas get easier targets?

Q.17 A) If I asked one of your staff members directly about individual targets, what would they tell me? B) Does anyone complain that the targets are too complex? Could every staff member employed by the school tell me what they are responsible for and how it will be assessed? C) How do people know about their own performance compared to other peoples performance?

Q18. A) How does your evaluation system work? What proportion of your employees' pay is related to the results of this review? B) Are there any non-financial or financial bonuses/ rewards for the best performers across all staff groups? How does the bonus system work (for staff and teachers)? C) How does your reward system compare to that of other schools? 
Continuation of Table A2

People: "Removing Poor Performers"

Q19. A) If you had a teacher who was struggling or who could not do his/ her job, what would you do? Can you give me a recent example? B) How long is underperformance tolerated? How difficult is it to terminate a teacher? C) Do you find staff members/ teachers who lead a sort of charmed life? Do some individuals always just manage to avoid being fired?

People: "Promoting High Performers"

People: "Managing Talent"

People: "Retaining Talent"

People: "Creating a Distinctive Employee Value Proposition"

Q20. A) Can you tell me about your career progression/ promotion system? B) How do you identify and develop your star performers? C) What types of professional development opportunities are provided? How are these opportunities personalised to meet individual teacher needs? D) How do you make decisions about promotion/ progression and additional opportunities within the school, such as performance, tenure, other? Are better performers likely to be promoted faster, or are promotions given on the basis of tenure/ seniority?

Q21. A) How do school leaders show that attracting talented individuals and developing their skills is a top priority? B) How do you ensure you have enough teachers of the right type in the school? C) Where do you seek out and source teachers? D) What hiring criteria do you use?

Q22. A) If you had a top performing teacher who wanted to leave, what would the school do? B) Could you give me an example of a star performer being persuaded to stay after wanting to leave? C) Could you give me an example of a star performer who left the school without anyone trying to keep him?

Q23. A) What makes it distinctive to teach at your school, as opposed to other similar schools? If you were to ask the last three candidates would they agree? Why? B) How do you monitor how effectively you communicate your value proposition and the following recruitment process? 